
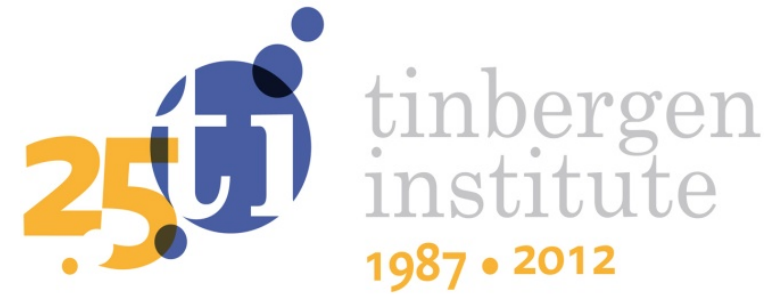

\title{
Democracy and Regulation: The Effects of Electoral Competition on Infrastructure Investments
}

\author{
Arthur Schram* \\ Aljaz Ule
}

Faculty of Economics and Business, University of Amsterdam.

* Tinbergen Institute 
Tinbergen Institute is the graduate school and research institute in economics of Erasmus University Rotterdam, the University of Amsterdam and VU University Amsterdam.

More TI discussion papers can be downloaded at http://www.tinbergen.nl

Tinbergen Institute has two locations:

Tinbergen Institute Amsterdam

Gustav Mahlerplein 117

1082 MS Amsterdam

The Netherlands

Tel.: +31(0)205251600

Tinbergen Institute Rotterdam

Burg. Oudlaan 50

3062 PA Rotterdam

The Netherlands

Tel.: +31(0)10 4088900

Fax: $+31(0) 104089031$

Duisenberg school of finance is a collaboration of the Dutch financial sector and universities, with the ambition to support innovative research and offer top quality academic education in core areas of finance.

DSF research papers can be downloaded at: http://www.dsf.nl/

Duisenberg school of finance

Gustav Mahlerplein 117

1082 MS Amsterdam

The Netherlands

Tel.: +31(0)20 5258579 


\title{
Democracy and Regulation: The Effects of Electoral Competition on Infrastructure Investments
}

\author{
Arthur Schram* \\ Aljaž Ule**
}

March 15, 2013

\begin{abstract}
:
This paper investigates infrastructure investment in markets where regulation is subject to varying degrees of manipulation by elected politicians. Based on a model of price regulation in a market with increasing demand and long-term returns on investment we construct a multi-period game between a service provider, consumers with voting rights and elected decision makers. In each period the consumers elect a decision maker who may then regulate the price for service provision. Before an election the service provider chooses whether to increase its capacity. Investment is irreversible and profitable only with a sufficiently high price. We derive the subgame perfect equilibrium for this game and investigate the price and investment dynamics through an experiment with human subjects. The experimental results show that service providers invest when decision-makers' interests align with their own, though prices may rise inefficiently high when the regulatory framework is made independent of future political manipulation. Independency of regulation thus decreases efficiency and consumer surplus. In contrast, when decision-makers' interests do not align with service providers' we find efficiency only when regulation can be made independent from electoral dynamics.
\end{abstract}

Key Words: Infrastructural investment; regulation;

JEL Codes: L5, L43,D92, C9

\section{Address:}

CREED and Tinbergen Institute

Amsterdam School of Economics

Roetersstraat 11

1018 WB Amsterdam

The Netherlands

*Schram@uva.nl.

**A.Ule@uva.nl

\section{Acknowledgments}

The research in this paper was funded by CPB in Den Haag. We are grateful to Rob Aalbers, Victoria Shestalova and Gijsbert Zwart of the CPB for useful suggestions at various stages of the research project. 


\section{Introduction}

In the worldwide wave of privatization of state-owned natural monopolies that characterizes the past three decades, unbundling of infrastructure and operations has been a consistent policy (Kessides 2004, Klein and Gray 1997). This implies a vertical separation of ownership of elements where competition is possible from those where natural monopoly is believed to exist. This way of privatizing natural monopolies has been widely used for utilities like electricity and natural gas, where the provision of an infrastructure is separated from the generation and distribution of the utility. This allows for competition in distribution that is not hindered by the natural monopoly characteristics of the infrastructure. ${ }^{1}$ Whereas regulation in the competitive environments of the operations can be minimized, the remaining natural monopoly of the infrastructure is typically regulated.

The separation of infrastructure from distribution comes at a potential cost, however. Technological progress and other developments in the markets from which the infrastructure has been separated may require substantial adjustments to the infrastructure itself. It is unclear whether the separation of operations provides proper incentives to invest towards such adjustments, especially in the regulated environment. Consider, for example, a competitive market for the generation and distribution of electric power, that has been vertically separated from the supply of the infrastructure (cables, etc.) by a (regulated) network operator. Both the demand and the supply side of the competitive market are subject to rapid development. On the one hand, the demand for electricity is expected to rise rapidly in the foreseeable future (e.g., due to the further development of heat pumps and electric cars; cf. Campillo et al. 2012; van Vliet et al. 2011, respectively). On the other hand, new technology has enabled decentralized generation of electricity via, e.g., micro-CHP ${ }^{2}$, solar panels, or rooftop wind mills.

As a consequence of these developments on both sides of the market, the demand for the service provided by the infrastructure may rise strongly in the near future and its operator may need to invest substantially in its expansion. ${ }^{3}$ Infrastructural investments are risky,

\footnotetext{
${ }^{1}$ Another prime example is the privatization of railways, where responsibility for the railway infrastructure is typically allocated to a different company than those who transport passengers and freight (Cox et al, 2001). For a discussion of the effects of electoral competition in this context, see Ponti and Erba (2002).

${ }^{2}$ Micro-CHP involves a combined generation of heat and power. It allows, for example, a household that uses natural gas for heating to generate electricity as a by-product. If it generates more than it uses, it can supply electricity to the network.

${ }^{3}$ To illustrate the cases we are interested in, we use here the example of investment in electricity transmission capacity. Other infrastructural investments may also be required. E.g., an increased demand for electricity due to
} 
however, not only because the future developments of demand and supply, which depend on the rate of technological change, are uncertain. Investments also have to be recouped from regulated tariffs. Investment lifetimes are very long (over 20 years), and the regulation may change during the long payback period after the investment, causing uncertainty over remuneration for the network owners.

This paper focuses on the effects of the latter form of uncertainty. We theoretically and experimentally analyze how the lack of commitment power from a regulator, arising from her vulnerability to public or political pressure, may influence network investment and the resulting market performance. Such pressure is most prominent in democratic environments, where regulation is governed by elected representatives, who have a desire to be reelected. Typically, these representatives can force a regulator to adjust the regulatory scheme, which will affect the profits of the monopolist responsible for the infrastructure (henceforth referred to as the 'infrastructure operator'). The latter, recognizing this possibility, may react by lowering or postponing her investment, thereby increasing the probability of constrained capacity, congestion, and low efficiency.

The use of laboratory experiments allows us to implement variations in types of regulation with a high degree of control. ${ }^{4}$ For example, laboratory control allows us to take away the uncertainty related to the future development of infrastructural utilization and isolate the uncertainty related to the variation in future prices caused by changes in regulation. It also allows us to systematically vary the extent to which the regulator's interests are aligned with those of the infrastructure operator. Such control thus allows us to study the effects of variations in the regulatory framework and in the regulator's preferences under conditions that are strongly ceteris paribus. More generally, this kind of control has made laboratory experiments a popular method for studying issues related to various markets (e.g., Brunner et al. 2010), including electric power markets (Rassenti et al. 2002; Staropoli and Jullien 2006; Brandts and Schram 2008; Brandts et al. 2012).

The experimental design is based on a model of a market with increasing demand over time and long-term returns on investment. In the model, the infrastructure operator must decide about investing in an environment where current and future prices in the market are

heat pumps and cars may require investments in so-called 'smart grids'. More generally, however, our framework covers different types of infrastructural investments.

${ }^{4}$ Falk and Heckman (2009) provide a recent methodological discussion of the advantages and disadvantages of laboratory experiments. Aside from the control discussed in the main text, one important advantage is the possibility of replication of results. 
determined by a regulator. The regulator's future decisions are subject to possible political manipulation. For this purpose, we construct a six-player multi-period game between one infrastructure operator, two political decision makers competing for office, and three consumers (with voting rights). In each period the consumers elect a decision maker who may then influence the regulated (per unit) price for use of the infrastructure. As discussed below, we will distinguish between four different regulatory frameworks that to various degrees constrain the decision maker's possibility to change the regulated price. We also systematically vary the extent to which the decision makers' interests are aligned with those of the infrastructure operator.

Before an election the infrastructure operator chooses whether to increase its capacity against an investment cost. Investment is irreversible and profitable only with a sufficiently high price for service provision. The infrastructure operator therefore faces (political) uncertainty about future prices -and, hence, about the profitability of investments- when deciding whether to invest. In the subgame perfect equilibrium of this game, the investment decision depends mainly on the regulatory framework. The infrastructure operator will only invest (in equilibrium) if the framework allows the elected decision maker to fully commit to a sufficiently high price in all future periods.

The experimental results provide only limited support for the comparative static predictions that equilibria entail. In particular, when the elected decision-maker's interests follow those of the infrastructure operator, we observe efficient investments. Such interests also lead to inefficiently high prices, however, in particular when the regulatory framework is rigid, that is, when the political decision maker sets up price regulation and then grants it independence beyond future elections. When the infrastructure operator's interests are not aligned with those of the infrastructure operator, the prices remain low. In this case, efficient investment is only observed with rigid regulation. In other regulatory frameworks, there is too little investment, which is caused by the fact that electoral competition pushes (regulated) prices down to levels that are beneficial to consumers in the short run, but hurts them in the long run.

The remainder of this paper is as follows. The following section introduces the model that we use and includes the equilibrium analysis. This is followed by our experimental design and procedures in section 3 . Section 4 gives our results and section 5 offers a conclusion. 


\section{Theoretical Model}

We structure our analysis and our experiment around a stylized game-theoretic model of investment in an industry where the decision makers -concerned about reelection- choose price regulation. Our notation is inspired by the example of electricity transmission regulation, involving an owner of a transmission network, electricity consumers with voting rights, and elected decision makers with varying freedom to regulate transmission charges. In this example electricity trade and production are assumed competitive and do not affect the conclusions below. We first describe and analyze a general model and then present and discuss the treatments used in the experiment. In the next section we describe and analyze the model with the specific parameters used in our experimental treatments.

An economy consist of the following agents:

- One infrastructure operator (IO). IO decides whether or not to invest in infrastructure. We assume that it always maximizes its profit through pricing, which may be restrained by regulation.

- A set of available decision-makers (DM). One decision maker is elected into office, denoted by $\mathrm{DM}^{\mathrm{E}}$, and may decide on the regulation of (electricity) infrastructure usage price. The non-elected decision-makers make no decisions.

- A set of n consumers/voters (CV). Voters choose $\mathrm{DM}^{\mathrm{E}}$ and consume electricity.

Investment relaxes capacity constraints imposed by the infrastructure. It also involves cost $c$ for the investor, which can be recuperated through charges from the extra service it enables. For simplicity we assume that $\mathrm{IO}$ accommodates a quantity of service up to $Q^{\text {cst }}$ with no investment, but can meet an unlimited demand for service if it does invest into its infrastructure. ${ }^{5}$ The capacity constraint is binding only when consumer demand for IO's service is sufficiently high. In this case consumers benefit from investment as it allows them higher consumption. Their preferences regarding price and investment may be in conflict, however: on one hand the consumers prefer prices that are low, on the other they prefer that IO invests into infrastructure, for which IO may require prices to stay high.

\footnotetext{
${ }^{5}$ Electricity transmission networks face low marginal costs for normal capacity but steeply increased marginal costs when capacity reaches network constraints (Brandts et al. 2008). We model this by assuming that transmission is costless when capacity is not reached, but has an infinite cost when capacity is exceeded. Cost $c$ can be seen as the rental cost of invested capital. We assume in the paper that it is incurred in every period after investment has been made.
} 
This conflict appears already with simple linear and additive demand functions. Let each consumer's demand for IO's service be given by $q(P)=b\left(P^{\max }-P\right)$ for $P \in\left[0, P^{\max }\right]$ and let the market demand be $Q(P)=n b\left(P^{\max }-P\right)$. We show in Appendix A that an unregulated profit maximizing IO invests and charges the monopoly price $P^{*}=\frac{1}{2} P^{\max }$ only when the demand sufficiently exceeds the capacity constraint,

$$
\frac{n b}{2} P^{\max }>Q^{c s t}
$$

and when the investment cost is sufficiently small,

$$
c<\frac{n b}{4}\left(P^{\max }\right)^{2}-\left(P^{\max }-\frac{1}{n b} Q^{c s t}\right) Q^{c s t} .
$$

Similarly, if regulation allows IO to charge at most price $P^{\text {reg }}<P^{*}$ then IO charges price $P=P^{r e g}$ and invests when the demand sufficiently exceeds the capacity constraint,

$$
n b\left(P^{\max }-P^{r e g}\right)>Q^{c s t},
$$

and when the investment cost is sufficiently small,

$$
c<n b P^{r e g}\left(P^{\max }-P^{r e g}\right)-P^{r e g} Q^{c s t} .
$$

From (4) it is clear that, given a fixed investment $\operatorname{cost} c$ and maximum price $P^{\text {reg }}>0$, investment is profitable for IO only with sufficiently high $n, b$ or $P^{\max }$, that is, when the aggregate demand is sufficiently high.

Consumers maximize their total surplus, after investment (with unconstrained infrastructure) given by $\pi^{V}(P)=\frac{n b}{2}\left(P^{\max }-P\right)^{2}$; before investment (with constrained infrastructure) given by $\pi^{V}(P)=\min \left\{\frac{n b}{2}\left(P^{\max }-P\right)^{2}, Q^{c s t}\left(1-\frac{1}{2 n b} Q^{c s t}\right)\left(P^{\max }-P\right)\right\}$. It is clear from this that consumers prefer low prices -which might prohibit investment- but at the same time prefer investment when their demand is sufficiently high.

The preferences of decision makers are not specified in this model. We consider three cases in this paper: ${ }^{6}$

[CA] Preferences of all DMs are aligned with those of consumers.

[IA] Preferences of all DMs are aligned with those of infrastructure owners.

[N] Preferences of all DMs are neutral, their only care is to be elected.

\footnotetext{
${ }^{6}$ An alternative case would be that DMs' interests are aligned with total surplus. We do not consider this case of a benevolent dictator in the current paper but see it as a possibility for future research. We will discuss efficient prices after presenting the experimental design.
} 
Throughout this paper we assume that the alignment of DMs' preferences is common knowledge. ${ }^{7}$ Though this is a strong assumption, voters generally do have ideas about politicians' motives, which are revealed through past policies. Consumers, however, do not have complete information: they do not know IO's payoff structure. As a consequence, they do not know DMs payoffs in the IA case, either. In contrast, the IO and DMs are assumed to be better informed and know CVs' payoffs.

Finally, when regulation limits the set of possible prices below the monopoly price, the IO always chooses the maximal possible price $P^{r e g}$. We therefore assume that regulation by $\mathrm{DM}^{\mathrm{E}}$ consists of choosing price $P^{\text {reg }}<P^{*}$ which the IO has to charge.

To obtain theoretical predictions we need to specify the sequence of decisions and determine subgame perfect equilibria (SPE). We begin with the analysis of the game when all decisions are taken just once. This game consists of the following consecutive steps:

1. IO decides whether or not to invest. If it invests it eliminates its capacity constraints and incurs cost $c$.

2. CVs vote to choose a DM that may regulate IO's price. The DM with a majority of votes becomes $\mathrm{DM}^{\mathrm{E}}$, where a random draw breaks ties in voting.

3. $\mathrm{DM}^{\mathrm{E}}$ chooses price $P^{\text {reg }}$, adopted by IO.

The SPE of this game depend on the size of demand and on the DMs' preferences. For this (one-shot) version of the game, we find the following equilibrium. IO never invests with low demand, while with high demand investment depends on the DMs' preferences. With [CA] preferences $\mathrm{DM}^{\mathrm{E}}$ will set $P^{\text {reg }}=0$ and the $\mathrm{IO}$ will never invest. With $[\mathrm{N}]$ preferences the DMs are unpredictable, but the consumers vote for the DM who would set the lowest price, which may lead to the race to the bottom and the same outcome as above. ${ }^{8}$ With [IA] preferences the $\mathrm{DM}^{\mathrm{E}}$ will set $P^{\text {reg }} \geq P^{*}$ (that is, it will abstain from regulation); the IO will charge the monopoly price $P^{*}$ and invest whenever conditions (1) and (2) above are satisfied.

The above game does not feature communication between the agents that may be present in real economies. In our experiment we therefore add communication: between steps 1 and 2

\footnotetext{
${ }^{7}$ Note that the three cases are chosen so as to compare extreme situations. In reality, alignment with IO seems more likely than with CV (Enikolopov 2012), because (i) a natural choice for a politician's post career employment is in industry; (ii) an IO will typically have much more effective lobbying power than CV; (iii) an IO has a strong incentive to offer future benefits (e.g., employment) to the DM.

${ }^{8}$ Strictly speaking, there are multiple SPE because the elected DM is indifferent between regulation prices. Any price can be achieved in an equilibrium where all DMs choose the same price if elected.
} 
the IO and the DMs each announce a suggestion for price $P^{\text {reg }}$. These announcements may serve as guidance to the CVs for their voting, but are formally just cheap talk and do not affect the equilibrium investment and price.

We now shift our focus to the extended game where agents make their decisions repeatedly. Our main aim is to investigate environments where investment is a long-term commitment relative to the electoral cycle with an uncertain regulatory dynamics. For this we consider an extended game where steps 1-3 above repeat $T$ times, with the following exceptions:

1a. Investment is irreversible: the IO retains the power to decide only until it actually invests. More precisely, if the IO did not invest in any previous period then it faces the decision whether to invest in period $t$. However, if it did invest in an earlier period then IO does not make any decision; it incurs cost $\mathrm{c}$ and all agents benefit from the increased capacity in each of the remaining periods $t . . . T$.

3a. Depending on the regulatory framework, $\mathrm{DM}^{\mathrm{E}}$ may face restrictions or costs when choosing price $P^{\text {reg }}$. We consider four regulatory frameworks: ${ }^{9}$

[UR] Unstable Regulation: $\mathrm{DM}^{\mathrm{E}}$ can choose $P^{\text {reg }}$ in every period without restrictions. [CR] Costly Regulation: $\mathrm{DM}^{\mathrm{E}}$ can change $P^{\text {reg }}$ between periods only against a cost. [SR] Stable Regulation: only the $\mathrm{DM}^{\mathrm{E}}$ elected in period 1 can choose $P^{\text {reg }}$ which then becomes fixed. In later periods this regulated price cannot be changed and the $\mathrm{DM}^{\mathrm{E}}{ }_{\mathrm{S}}$ elected in periods $2 \ldots T$ make no decisions.

[ER] Endogenous Regulation: initially the $\mathrm{DM}^{\mathrm{E}}$ makes two decisions; it chooses $P^{\text {reg }}$ and decides whether to fix the regulation for the remaining periods. If it does not fix this price then the DM elected in the next period faces the same situation. If, however, it decides to fix its chosen $P^{r e g}$, it remains fixed forever and the $\mathrm{DM}^{\mathrm{E}}$, $\mathrm{s}$ elected in later periods make no decisions. In other words, the game starts with unstable regulation but an elected $\mathrm{DM}^{\mathrm{E}}$ can choose to stabilize it in any period.

\footnotetext{
${ }^{9}$ Admittedly, the regulation in real markets rarely imposes a single price. The actual regulation of electricity transmission charges in the Netherlands determines how the maximum charge changes with the consumer price index (CPI). Evidence from transmission charges in the Netherlands show that network operators almost always charge the maximal possible price, however. We simplify this in our model by assuming a constant CPI and a single (maximal) regulated price. This leads to regulation with a constant regulated price.
} 
We assume that all agents maximize the sum of the payoffs earned across the periods. Moreover, inspired by the example of electricity transmission we assume that demand increases with periods. The first period that makes investment efficient ${ }^{10}$ is denoted by invr ${ }^{e}$, the first period that makes investment profitable for IO when price $P^{\text {reg }}$ is stable (fixed) across periods is denoted by $\operatorname{invr}\left(P^{\text {reg }}\right)$.

Interestingly, the SPE of this extended (repeated) game are less dependent on the DMs' preferences than the SPE of the simpler (one-shot) game. This is because $\mathrm{DM}^{\mathrm{E}}$ cares about reelection, as non-elected DMs earn nothing. CVs can use this to credibly threaten $\mathrm{DM}^{\mathrm{E}}$ that does not regulate $P^{\text {reg }}$ in their favor. In particular, below we show how in all our treatments the CVs can enforce low prices in an SPE through the following combination of strategies:

$\mathrm{CV}$ : "Vote for DM1 in period 1. In period $t$ vote for the same DM as in period $t-1$ as long as she did everything in her power (choosing and perhaps fixing the price) to achieve the price that across the remaining periods is best for $\mathrm{CVs}$ and still profitable for DM. In the opposite case vote for the other DM."

DM: "Always choose the regulation requested by the CVs, with one possible exception: in the final period $T$ choose the best price for yourself if change of regulation is cheap and possible."

IO: "Invest in period $\operatorname{invr}(P)$ if and only if given above strategies, $P^{\text {reg }} \geq P>0$ is certain for all subsequent periods.”

Assuming voter's behavior, this SPE is given by backwards induction. ${ }^{11}$ Obviously, with [CA] and $[\mathrm{N}]$ preferences the DM elected in period 1 has no reason to deviate and will be reelected in all subsequent periods. Consider now [IA] preferences. The $\mathrm{DM}^{\mathrm{E}}$ in the last period $T$ will profit from being elected. Because of increasing demand she profits more from waiting with her preferred (monopoly) price until period $T$ than to choose it in period $T-1$ and lose the election in period $T$. If other DMs use the above strategy, a DM that loses an election never returns to office. By induction the above argument therefore extends to all periods. Finally, the assumed CVs' voting is rational given DM and IO strategies.

\footnotetext{
${ }^{10}$ We measure efficiency with the total surplus from network service. Given our assumption on zero marginal costs the surplus is calculated as the sum of IO's and all CVs' profits.

${ }^{11}$ Strictly speaking, any outcome can emerge in an equilibrium of such a voting game, because three voters voting for the same candidate is always an equilibrium. Multiple equilibria are typical for voting games with obligatory voting. To avoid the folk-theorem type result for the SPE of the (repeated) game we assume the voters behavior. For a further discussion of this multiple voting equilibria problem, see Banks \& Duggan (2006).
} 
The exact calculation of SPE prices, regulation and investment depends on the details of the demand function dynamics. In the next section we describe the model parameters that we implemented in our experiments. We then determine the detailed equilibrium behavior for all our treatments.

\section{Experimental Design and Procedures}

\section{General Setup}

The experimental design implements the model of section 2 with groups of six subjects, consisting of one infrastructure operator, two (political) decision makers and three consumers with voting rights. Groups and roles are fixed throughout the nine periods of the computerized experiment. A translation of the Dutch instructions is given in Appendix B. In these instructions, the IO is introduced as an "investor" and the political decision makers as "price determiners". All subjects are told:

"In every period, the investor delivers to each consumer a good. Exactly the same good is delivered to each consumer. Every consumer must buy the product. The price of the product is determined by one of the price determiners."

Subsequently, they are told that the investor must decide on investing in the production process and that consumers elect by majority vote which of the two decision makers will be allowed to set the price in a period. In the experiment, the set of prices from which can be chosen consists of the integers $\{0,1,2,3,4,5\}$.

Each period then consists of six steps, which were taken sequentially:

Step I: If the investor has not previously invested in high capacity, she decides whether to do so. If she has previously invested, capacity remains high (no decision is needed).

Step II: The investor publicly announces a desired price for the good.

Step III: The price determiners simultaneously and publicly each announce a target price for the good. ${ }^{12}$

Step IV: Each consumer votes for one of the two price determiners. The price determiner with two or more votes is elected.

$\underline{\text { Step V}}$ : The elected price determiner sets the price for the period. ${ }^{13}$

\footnotetext{
${ }^{12}$ Note that steps II and III are cheap talk and do not imply any kind of commitment.
} 


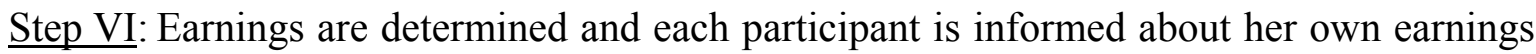
in the period concerned.

\section{Earnings}

Earnings in the experiment are denoted by "experimental Franks". At the end of a session, these are exchanged for euros at a rate of $€ 1$ for 50 Franks. Decision makers are given a starting capital of 325 Franks to avoid negative earnings. The instructions inform all subjects that additional earnings depend on (i) whether or not the investor has invested; and (ii) the price chosen by the price determiner. All subjects are subsequently told that the following general rules hold:

- investing never harms the consumers' earnings and often increases them;

- higher prices are usually better for the investor;

- lower prices are better for the consumer;

- the price determiner that is not elected in a period earns nothing;

- the elected price determiner earns [.....].

The earnings of the elected price determiner shown in the last bullet depend on its preferences which differ between treatments, as will be explained below.

On their computer monitor the subjects are shown the possible earnings in a period in a two dimensional table that discriminates between the six possible prices $\{0,1,2,3,4,5\}$ and whether or not an investment has taken place. For each price-investment combination the investors and decision makers are shown the earnings of each type of participant whereas consumers see only their own earnings. ${ }^{14}$ When subjects have finished reading the (computerized) instructions and before the experiment itself is started, they receive a table showing the payoffs of all nine periods.

The payoffs are based on the model from Section 2 above, with parameters $P^{\max }=6+t, b=2$, $\mathrm{n}=3, \mathrm{Q}^{\mathrm{cst}}=15$ and $\mathrm{c}=20$, where $\mathrm{t} \in\{1,2, \ldots, 9\}$ denotes the period. For simplicity we permit just discrete values for the price. These cover the most interesting cases. Figure 1 shows the resulting payoff tables of investors and consumers (payoffs of price determiners will be described below).

\footnotetext{
${ }^{13}$ As will be explained below (and is discussed above), in some treatments the price is fixed across periods. In these cases no choice is required in step V.

${ }^{14}$ This asymmetry was chosen for external validity reasons. We doubt that most consumers know the details about the consequences of specific price-investment combinations, instead relying on general notions such as 'high prices are good for producers'. Producers and politicians are generally better informed.
} 
Figure 1: Payoff tables

Investor's earnings; no investment

\begin{tabular}{|c|ccccccccc|}
\multicolumn{1}{l}{$P^{\text {reg }}$} & 1 & 2 & 3 & 4 & 5 & 6 & 7 & 8 & 9 \\
\hline 0 & 0 & 0 & 0 & 0 & 0 & 0 & 0 & 0 & 0 \\
1 & 30 & 30 & 30 & 30 & 30 & 30 & 30 & 30 & 30 \\
2 & 60 & 60 & 60 & 60 & 60 & 60 & 60 & 60 & 60 \\
3 & 72 & 90 & 90 & 90 & 90 & 90 & 90 & 90 & 90 \\
4 & 72 & 96 & 120 & 120 & 120 & 120 & 120 & 120 & 120 \\
5 & 60 & 90 & 120 & 150 & 150 & 150 & 150 & 150 & 150 \\
\hline
\end{tabular}

Investor's earnings; investment

\begin{tabular}{|c|ccccccccc|}
\multicolumn{1}{c}{$P^{\text {reg }}$} & 1 & 2 & 3 & 4 & 5 & 6 & 7 & 8 & 9 \\
\hline 0 & -20 & -20 & -20 & -20 & -20 & -20 & -20 & -20 & -20 \\
1 & 16 & 22 & 28 & 34 & 40 & 46 & 52 & 58 & 64 \\
2 & 40 & 52 & 64 & 76 & 88 & 100 & 112 & 124 & 136 \\
3 & 52 & 70 & 88 & 106 & 124 & 142 & 160 & 178 & 196 \\
4 & 52 & 76 & 100 & 124 & 148 & 172 & 196 & 220 & 244 \\
5 & 40 & 70 & 100 & 130 & 160 & 190 & 220 & 250 & 280 \\
\hline
\end{tabular}

Consumer's earnings; no investment

\begin{tabular}{|c|ccccccccc|}
\multicolumn{1}{c}{$P^{\text {reg }}$} & 1 & 2 & 3 & 4 & 5 & 6 & 7 & 8 & 9 \\
\hline 0 & 45 & 55 & 65 & 75 & 85 & 95 & 105 & 115 & 125 \\
1 & 35 & 45 & 55 & 65 & 75 & 85 & 95 & 105 & 115 \\
2 & 25 & 35 & 45 & 55 & 65 & 75 & 85 & 95 & 105 \\
3 & 16 & 25 & 35 & 45 & 55 & 65 & 75 & 85 & 95 \\
4 & 9 & 16 & 25 & 35 & 45 & 55 & 65 & 75 & 85 \\
5 & 4 & 9 & 16 & 25 & 35 & 45 & 55 & 65 & 75 \\
\hline
\end{tabular}

Consumer's earnings; investment

\begin{tabular}{|c|ccccccccc|}
\multicolumn{1}{c}{$P^{\text {reg }}$} & 1 & 2 & 3 & 4 & 5 & 6 & 7 & 8 & 9 \\
\hline 0 & 49 & 64 & 81 & 100 & 121 & 144 & 169 & 196 & 225 \\
1 & 36 & 49 & 64 & 81 & 100 & 121 & 144 & 169 & 196 \\
2 & 25 & 36 & 49 & 64 & 81 & 100 & 121 & 144 & 169 \\
3 & 16 & 25 & 36 & 49 & 64 & 81 & 100 & 121 & 144 \\
4 & 9 & 16 & 25 & 36 & 49 & 64 & 81 & 100 & 121 \\
5 & 4 & 9 & 16 & 25 & 36 & 49 & 64 & 81 & 100 \\
\hline
\end{tabular}

Notes. Cells denote payoffs in Franks for each period (column) for each of the six possible prices (row). Investors and price determiners were shown all four tables; consumers only saw the lower two.

During the experiment the subjects also have access to a calculation aid' on their monitor, with which they can calculate the payoff consequences of all possible combinations of prices and investments in the remaining periods. Figure 2 provides an example of this aid. 


\section{Figure 2: Calculator}

Notes. Subjects choose a price for each remaining period and click a period for investment (if any). All later periods are then automatically also selected. Decisions for

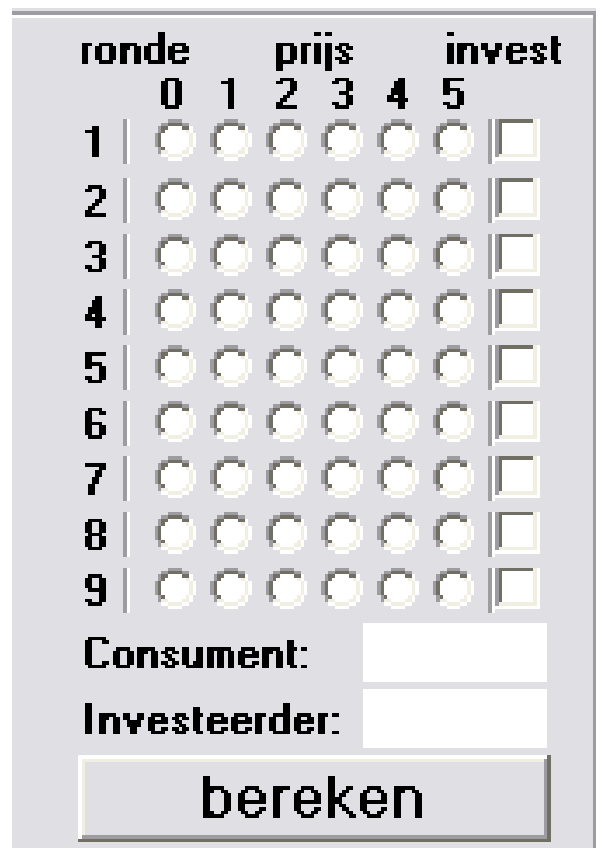

periods that have already passed can no longer be entered. If the investor has invested in a previous period, investment is automatically selected for all remaining periods. This example calculates and shows cumulative payoffs for consumers and investors. Consumers are only shown their own payoffs. Translation: 'ronde' = period; 'prijs = price; 'consument'=consumer; 'investeerder'=investor.

\section{Treatments}

We vary treatments along two dimensions. First, we vary the earnings of the elected price determiner. In 'Investor Aligned' [IA], this price determiner earns exactly the same amount as the investor in a period. In 'Consumer Aligned' [CA] she earns the same as the consumer. Finally, in the treatment 'Non-aligned' [N], the price determiner earns 75 Francs if elected. These treatments allow us to investigate the effects of variations in the alignment of a political decision maker's interests with those of the other actors.

The second treatment dimension varies the freedom that an elected price determiner $\mathrm{DM}^{\mathrm{E}}$ has in determining the price. In 'Unstable Regulation' [UR], the $\mathrm{DM}^{\mathrm{E}}$ is free to choose a 
price in any period. 'Stable Regulation' [SR] is the other extreme. Here, the price determiner that is elected in period 1 chooses a price that holds for all nine periods. In 'Endogeneous Regulation' [ER], fixing the price for future periods is optional. In any period, if the price has not yet been fixed in previous periods, the $\mathrm{DM}^{\mathrm{E}}$ chooses a price, and additionally decides whether that price will hold only in the period concerned or for all remaining periods. ${ }^{15}$ Finally, in 'Costly Regulation' [CR], the $\mathrm{DM}^{\mathrm{E}}$ can choose any price. If this price is different than the price chosen in the previous period, the $\mathrm{DM}^{\mathrm{E}}$ is charged 15 Franks (which is approximately $20 \%$ of $\mathrm{DM}^{\mathrm{E}}$, s period earnings). If the same price is chosen as in the previous period, there are no costs.

The two treatment dimensions were varied in a between-subject design. Table 1 summarizes the treatment combinations and shows the number of observations for each combination.

Table 1: Treatments

\begin{tabular}{|l|c|c|c|}
\hline & {$[\mathrm{CA}]$} & {$[\mathrm{IA}]$} & {$[\mathrm{N}]$} \\
\hline $\mathrm{UR}]$ & $\mathrm{n}=5$ & $\mathrm{n}=5$ & $\mathrm{n}=4$ \\
\hline$[\mathrm{SR}]$ & $\mathrm{n}=4$ & $\mathrm{n}=4$ & $\mathrm{n}=4$ \\
\hline$[\mathrm{ER}]$ & $\mathrm{n}=5$ & $\mathrm{n}=5$ & $\mathrm{n}=6$ \\
\hline$[\mathrm{CR}]$ & $\mathrm{n}=5$ & $\mathrm{n}=4$ & $\mathrm{n}=8$ \\
\hline
\end{tabular}

Notes. $\mathrm{n}$ denotes the number of groups in each treatment combination.[UR] Unstable Regulation; [SR] Stable Regulation; [ER] Endogeneous Regulation; [Costly Regulation]; $[\mathrm{CA}]=$ Consumer Aligned; [N]=Non-aligned; [IA $]=$ Investor Aligned.

\section{Procedures}

The experiments were run at the laboratory of the Center for Research in Experimental Economics and political Decision making (CREED) at the University of Amsterdam. Subjects were recruited from the CREED subject pool, which consists of approximately 2000 students, mainly UvA undergraduates from various disciplines. 324 subject participated and earned on average €27,42 (including a €7 show-up fee). Sessions lasted between 90 and 120 minutes.

Each session started with computerized instructions (Appendix B). When subjects had finished with these, a summary was handed out, as were the payoff tables. Subjects were given five minutes to study this material. Then every subject participated in a brief

\footnotetext{
${ }^{15}$ Due to a software error, price determiners in some groups were asked to determine a price even after this had previously been fixed. This had no consequences for earnings and progress of the game however, and we will neglect the decisions made in these cases when analyzing the data.
} 
measurement of aversion to commitment before the main experiment started. ${ }^{16}$ This experiment was programmed in Delphi. Before subjects were paid, they filled out a brief questionnaire soliciting background information.

\section{Theoretical Benchmarks}

We base equilibrium predictions on the SPE analysis given in Section 2, adapted for our parameters and the discrete price set in our 9-period game. Using the arguments and strategies from Section 2, Table 2 gives the SPE outcomes for all treatments. Below, we will present hypotheses based on the treatment differences implied by these predictions.

Table 2: Equilibrium prices and investment

\begin{tabular}{|c|c|c|}
\hline & {$[\mathrm{CA}]$ or $[\mathrm{N}]$} & [IA] \\
\hline [UR] & $\mathrm{P}^{\mathrm{reg}}=\{0, . ., 0\} ;$ invr $^{e}=$ never & $\mathrm{P}^{\mathrm{reg}}=\{0, . .0,5\} ;$ invr $^{e}=9$ \\
\hline [SR] & $\mathrm{P}^{\mathrm{reg}}=\{1, . ., 1\} ;$ invr $^{e}=4$ & $\mathrm{P}^{\mathrm{reg}}=\{1, . ., 1\} ;$ invr $^{e}=4$ \\
\hline [ER] & $\mathrm{P}^{\mathrm{reg}}=\{0,0,1, . ., 1\} ;$ fix in r. $3 ;$ invr $^{e}=4$ & $\mathrm{P}^{\mathrm{reg}}=\{0,0,1, . ., 1\} ;$ fix in r. $3 ;$ invr $r^{e}=4$ \\
\hline [CR] & $\mathrm{P}^{\mathrm{reg}}=\{0, . ., 0\} ; i n v r^{e}=$ never & $\mathrm{P}^{\mathrm{reg}}=\{0, . ., 0,5\} ;$ invr $^{e}=9$ \\
\hline
\end{tabular}

Notes. Treatments are defined in the note to Table $1 . \mathrm{P}^{\mathrm{reg}}=$ the regulated price. $\operatorname{Invr}^{\mathrm{e}}=$ the first period of investment.

The numbers in table 2 follow straightforwardly from the analysis in section 2 . Take, for example the (ER,IA) cell. If IO invests before the price is fixed, the voters will elect the DM that fixes the price to 0 . IO will therefore invest only after the price is fixed and if the fixed price is at least 1 . Given the price is fixed to 1 , IO invests in period 4. It is therefore optimal for the consumers that the price is fixed to 1 in round 3.

As a different benchmark than SPE, we consider efficiency. First, we determine the regulation for the situation where the DMs are only concerned with efficiency (neglecting their preferences) but the investors best respond to the anticipated regulation. This represents a situation where the DMs are social welfare maximizers. The efficient price after investment is $\mathrm{P}^{\mathrm{reg}}=0$, which makes investment unprofitable. The rational investor knows this and, faced with an efficiency concerned regulator, will invest only if the regulator fixes the price $\mathrm{P}^{\mathrm{reg}} \geq 0$. For example, in the treatments where the DMs cannot commit to a price (UR and CR), the investor realizes that prices will be set (back) to the efficient level 0 as soon as investment has taken place. Therefore, the investor will never invest and -conditional on non-

\footnotetext{
${ }^{16}$ The results of the commitment measurement proved uninformative for behavior in the main experiment and will not be discussed in this paper.
} 
investment - the efficient price $\mathrm{P}^{\mathrm{reg}}=0$ is chosen in each period. The second column in Table 3 shows the resulting outcomes.

As an alternative efficiency benchmark, we determine the most efficient outcome obtainable under the restriction that no agent makes a loss in any single period (implying only that the price must be 1 or more after IO invests). ${ }^{17}$ The third column in Table 3 shows the resulting outcomes. We will use these outcomes in our efficiency analyses.

Table 3: Efficient prices and investment

\begin{tabular}{|l|c|c|}
\hline & Efficient DM & No loss efficiency \\
\hline$[\mathrm{UR}]$ & $\mathrm{P}^{\mathrm{reg}}=\{0, . ., 0\} ;$ invest $=$ never & $\mathrm{P}^{\mathrm{reg}}=\{0,1 . ., 1\} ;$ invest $=\mathrm{r} 2$ \\
\hline$[\mathrm{SR}]$ & $\mathrm{P}^{\mathrm{reg}}=\{1, . ., 1\} ;$ invest $=\mathrm{r} 4$ & $\mathrm{P}^{\mathrm{reg}}=\{1, . .1\} ;$ invest $=\mathrm{r} 2$ \\
\hline$[\mathrm{ER}]$ & $\mathrm{P}^{\mathrm{reg}}=\{1, . ., 1\} ;$ fix $<4 ;$ invest $=\mathrm{r} 4$ & $\mathrm{P}^{\mathrm{reg}}=\{0,1, . ., 1\} ;$ invest $=\mathrm{r} 2$ \\
\hline$[\mathrm{CR}]$ & $\mathrm{P}^{\mathrm{reg}}=\{0, . ., 0\} ;$ invest $=$ never & $\mathrm{P}^{\mathrm{reg}}=\{0,1, . ., 1\} ;$ invest $=\mathrm{r} 2$ \\
\hline
\end{tabular}

For the sake of completeness, we consider the inequality involved in the various outcomes. Before investment, the most equal payoffs are obtained with price sequence $\{2,2,3,3,3,3,4,4,4\}$, but after investment the payoffs are most equal when $\mathrm{P}^{\mathrm{reg}}=2$ in all periods. Comparing this to the results in Tables 2 and 3 implies shows that observed prices of 2 or higher may be an indication of subjects with inequity aversion.

\section{Hypotheses}

We can use the equilibrium predictions of Table 2 to formulate several hypotheses and predict comparative statics in treatment comparisons.

H1. Investment will happen earlier in treatments that permit fixing the regulated price (SR and ER) than in treatments where the price cannot be fixed (UR and CR).

$\mathrm{H} 2$. Prices will be higher in treatments that permit fixing the regulated price (SR and ER) than in treatments where the price cannot be fixed (UR and CR).

H3. Except in the final period, the DMs' preferences do not affect investment or prices. In the final period the prices will be higher when the DMs' interests are aligned with those of the investor [IA] and the prices cannot be fixed (treatments [UR] and [CR]).

In addition, recall from section 2 that the equilibrium involves CVs voting for the incumbent $\mathrm{DM}$, if she previously chose the lowest price, conditional on her not making a loss (across all

\footnotetext{
${ }^{17}$ This represents the text book case of average cost pricing.
} 
periods). Note that this means that from period 2 onward, CVs vote to reelect after price 0 in UR and CR. In SR they reelect if the price is fixed at 1 in period 1 and in ER they do so after an unfixed price 0 in periods 2 or 3 and after a fixed price 1 in period 4 . This yields:

H4: Voters are less likely to vote to reelect the incumbent after she previously chose a price of 2 or more than after a lower price. In UR and CR, voters are less likely to vote to reelect the incumbent after she previously chose a price of 1 than after a price of 0 .

\section{Experimental Results}

In analyzing the experimental data, we will consider the effects that treatment variation has on average prices, the period of investment, and aggregate welfare. We will first provide a general overview of the results and subsequently analyze the data in more detail. We will end by formally testing the hypotheses derived in the previous section. All p-values reported in this section are based on two-sided tests.

\section{Partial treatment effects}

Figure 2 shows the development of prices (left panel) and investments (right panel) across the 9 periods, distinguishing between the three variations in alignment for the DMs' interests. The figure shows that prices are much higher (from the beginning) when the price determiners and the investor share common interests. Apparently, electoral competition for office is insufficient to bring prices down to the levels observed in the other two treatments. When price determiners have interests that are aligned with those of the consumers, prices start off low and remain so across the nine periods. Interestingly, a very similar pattern is observed when their interests are independent. Here, electoral competition does keep prices in line with the consumers' wishes (and the SPE). 
Figure 2: Investments and Prices by Alignment

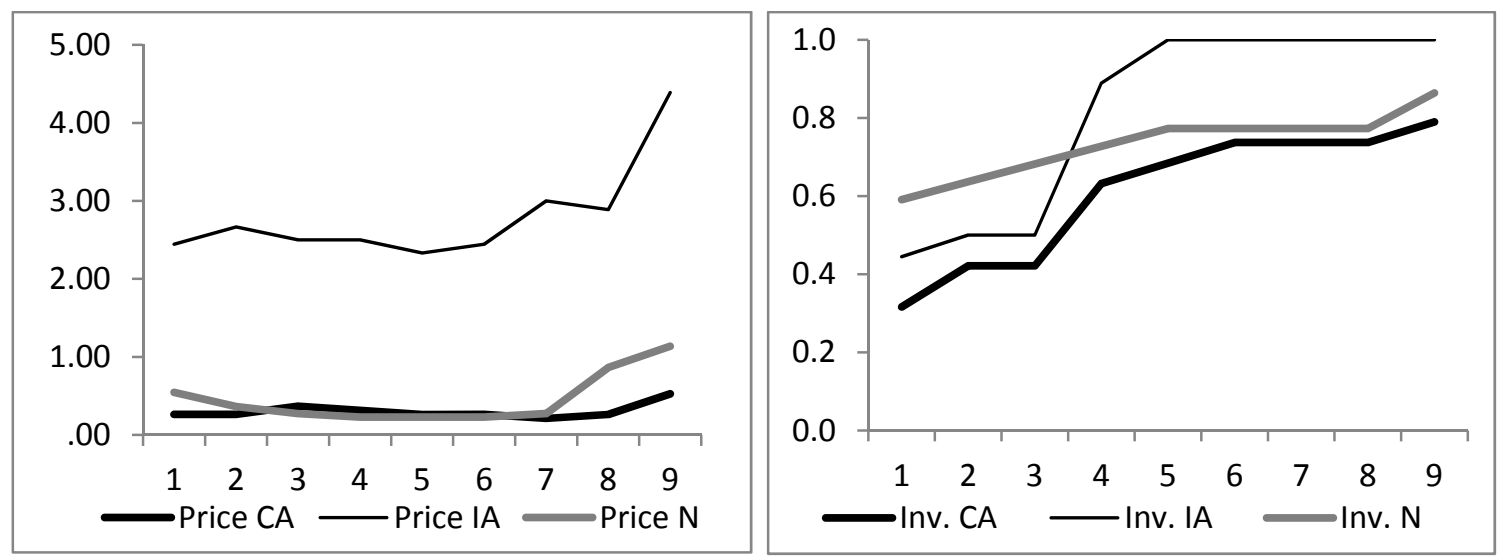

Notes. The left panel shows the average price (vertical axis) per period (horizontal axis). The right panel shows the fraction of groups in which investment ('Inv.') has occurred (vertical axis) for each period (horizontal axis). Inv. $=$ Investment; $[\mathrm{CA}]=$ Groups where the price determiners' interests are aligned with the consumers' interests; $[\mathrm{IA}]=$ Groups where the price determiners' interests are aligned with the Investor's interests; $[\mathrm{N}]=$ Groups where the price determiners have independent interests.

These price dynamics are only partly reflected in the investors' decisions. When they know that the DMs share their interests, in [IA], almost 50\% invest already in period 1 and all have invested by period 5. Recall that investing in periods 1-3 is never efficient (because with the efficient price the demand can be met with the constrained capacity). Investment in period 4 is optimal for the investor if prices are expected to stay at 1 or above. The jump in the fraction of investment from $50 \%$ in period 3 to $89 \%$ in period 4 seems to indicate that investors expect such prices in treatments [IA]. In treatments [CA], on the other hand, many investors seem to (rightfully) expect prices to stay at 0 . They invest at relatively low rates early on (starting at $32 \%$ ), but the rate gradually increases to $79 \%$. Interestingly, there is a strong increase in investments between periods 3 and 6 (from $42 \%$ to $74 \%$ ) that does not seem to be justified by changes in prices. Apparently, our investor subjects insufficiently take into account the fact that price determiners have no reason to increase prices once investments have taken place. ${ }^{18}$ Finally, the treatment with independent price determiners $[\mathrm{N}]$ shows that $59 \%$ of the investors invest already in period 1 . If they do so expecting high prices, they are disappointed as mostly the prices remain close to 0 . As a consequence, the subsequent increase in investment is limited.

\footnotetext{
${ }^{18}$ It is quite likely that experienced real-world investors will be less prone to such unjustified optimism about future prices. For reasons of external validity, we therefore prefer to look at cross-treatment differences. In this respect it is to be expected that investments are lowest in the CA treatments.
} 
Figure 3 shows the dynamics of the same two variables, now distinguishing across the second treatment variation, i.e., types of regulation.

Figure 3: Investments and Prices by Regulation

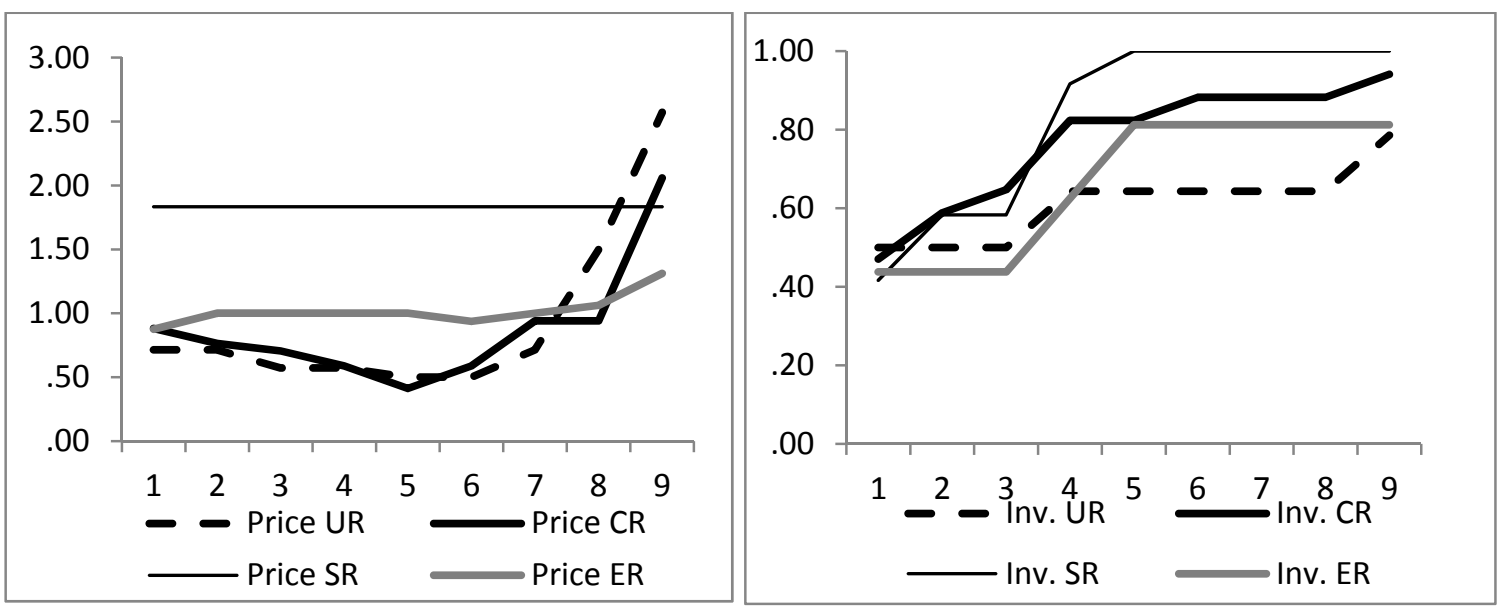

Notes. The left panel shows the average price (vertical axis) per period (horizontal axis). The right panel shows the fraction of groups in which investment ('Inv.') has occurred (vertical axis) for each period (horizontal axis). Inv. =Investment; [UR]=Unstable Regulation (prices freely chosen each period); [CR]: Costly Regulation (prices changed at a cost); [SR]: Stable Regulation (prices fixed in period 1); [ER]: Endogenous Regulation (price determiner chooses whether or not to fix the price).

At first sight, differences across regulation types are smaller than across alignments. ${ }^{19}$ The treatment that stands out is [SR], where prices are chosen and fixed, in period 1. This yields the highest prices and the maximum investment rate from period 5 onward. Otherwise, prices in UR and CR show only small differences. This means that the costs related to changing the price from one period to the next ( 0 in UR and $20 \%$ of earnings in CR) have little effect on the price. Nevertheless, IOs seem to invest slightly earlier when it is costly to change regulation. Finally, average prices are quite stable when the price determiner can choose to fix them (ER). This yields investments that almost double from $44 \%$ to $81 \%$ between periods 3 and 5. Below, we investigate in more detail how our subjects choose to fix the price.

Finally, note an end effect in some treatments, seen in figures 2 and 3 in the last periods. For this reason, we will present some results based on the first six periods only, excluding the end-game effects. The number of electoral periods outside of the laboratory is typically not limited.

\footnotetext{
${ }^{19}$ Below, we provide statistical tests of differences across treatments.
} 


\section{Combined treatment effects}

Next, we consider combinations of the two treatment variations. Table 4 presents an overview of some key statistics.

Table 4: General Overview of the Results

\begin{tabular}{|c|c|c|c|c|}
\hline & $\mathrm{CA}$ & $\mathrm{IA}$ & $\mathrm{N}$ & Total \\
\hline \multirow{5}{*}{ UR } & $\mathrm{P} 9=0.09$ & $\mathrm{P} 9=2.11$ & $\mathrm{P} 9=0.50$ & $\mathrm{P} 9=0.93$ \\
& $\mathrm{P} 6=0.07$ & $\mathrm{P} 6=1.50$ & $\mathrm{P} 6=0.13$ & $\mathrm{P} 6=0.60$ \\
& $\mathrm{I} 6=3.60$ & $\mathrm{I} 6=1.20$ & $\mathrm{I} 6=3.00$ & $\mathrm{I} 6=2.58$ \\
& $\mathrm{E} 9=0.84$ & $\mathrm{E} 9=0.95$ & $\mathrm{E} 9=0.87$ & $\mathrm{E} 9=0.89$ \\
\hline \multirow{5}{*}{ CR } & $\mathrm{P} 9=0.31$ & $\mathrm{P} 9=2.64$ & $\mathrm{P} 9=0.35$ & $\mathrm{P} 9=0.93$ \\
& $\mathrm{P} 6=0.30$ & $\mathrm{P} 6=2.13$ & $\mathrm{P} 6=0.15$ & $\mathrm{P} 6=0.66$ \\
& $\mathrm{I} 6=1.80$ & $\mathrm{I} 6=1.50$ & $\mathrm{I} 6=1.86$ & $\mathrm{I} 6=1.74$ \\
& $\mathrm{E} 6=0.99$ & $\mathrm{E} 9=0.93$ & $\mathrm{E} 9=0.93$ & $\mathrm{E} 9=0.95$ \\
\hline \multirow{5}{*}{ ER } & $\mathrm{P} 9=0.50$ & $\mathrm{P} 9=4.25$ & $\mathrm{P} 9=0.75$ & $\mathrm{P} 9=1.83$ \\
& $\mathrm{P} 6=0.50$ & $\mathrm{P} 6=4.25$ & $\mathrm{P} 6=0.75$ & $\mathrm{P} 6=1.83$ \\
& $\mathrm{I} 6=2.52$ & $\mathrm{I} 6=1.26$ & $\mathrm{I} 6=0.78$ & $\mathrm{I} 6=1.50$ \\
& $\mathrm{E} 9=1.00$ & $\mathrm{E} 9=0.86$ & $\mathrm{E} 9=1.00$ & $\mathrm{E} 9=0.95$ \\
\hline & $\mathrm{P} 9=0.36$ & $\mathrm{P} 9=2.44$ & $\mathrm{P} 9=0.39$ & $\mathrm{P} 9=1.32$ \\
& $\mathrm{P} 6=0.33$ & $\mathrm{P} 6=2.33$ & $\mathrm{P} 6=0.36$ & $\mathrm{P} 6=0.97$ \\
& $\mathrm{I} 6=3.18$ & $\mathrm{I} 6=2.58$ & $\mathrm{I} 6=1.68$ & $\mathrm{I} 6=2.46$ \\
& $\mathrm{E} 9=0.88$ & $\mathrm{E} 9=0.95$ & $\mathrm{E} 9=0.95$ & $\mathrm{E}=0.93$ \\
\hline \multirow{5}{*}{ Total } & $\mathrm{P} 9=0.30$ & $\mathrm{P} 9=2.80$ & $\mathrm{P} 9=0.46$ & $\mathrm{P} 9=1.22$ \\
& $\mathrm{P} 6=0.29$ & $\mathrm{P} 6=2.48$ & $\mathrm{P} 6=0.31$ & $\mathrm{P} 6=0.97$ \\
& $\mathrm{I} 6=2.76$ & $\mathrm{I} 6=1.68$ & $\mathrm{I} 6=1.80$ & $\mathrm{I} 6=2.10$ \\
& $\mathrm{E} 9=0.92$ & $\mathrm{E} 9=0.93$ & $\mathrm{E} 9=0.94$ & $\mathrm{E} 9=0.93$ \\
\hline
\end{tabular}

Notes. For treatments acronyms, see Table 1. P9=average price across all 9 periods; $\mathrm{P} 6=$ average price periods 1 6; I6=average number of periods without investment, periods 1-6; E9= average efficiency across all 9 periods. $[\mathrm{UR}]=$ Unstable Regulation (prices freely chosen each period); [CR]: Costly Regulation (prices changed at a cost); [SR]: Stable Regulation (prices fixed in period 1); [ER]: Endogenous Regulation (price determiner chooses whether or not to fix the price). ; $[\mathrm{CA}]=$ the price determiners' interests are aligned with the consumers' interests; $[\mathrm{IA}]=$ the price determiners' interests are aligned with the Investor's interests; $[\mathrm{N}]=$ the price determiners have independent interests.

First, consider average prices. Note that the end effect observed in Figures 2 and 3 does not seem to have qualitative consequences for the comparisons across treatments. Nevertheless, to avoid possible confounds with such an end effect we base our statistical analyses on the first six periods, by investigating cross-treatment differences in the variable P6. ${ }^{20}$ These (average) prices differ significantly across the three DM alignment categories (Kruskal

\footnotetext{
${ }^{20}$ Note that this provides a conservative approach. Differences are larger for P9.
} 
Wallis -henceforth, KW-; $\mathrm{n}=59 ; \mathrm{p}<0.01)^{21}$. Considering each of the regulation treatments separately shows that alignment has a significant effect on prices in each. ${ }^{22}$ Hence, DMs' alignment affects prices, irrespective of the regulatory environment. Price differences across the regulation treatments are not significant $(\mathrm{KW} ; \mathrm{n}=59 ; \mathrm{p}=0.19)$. There are differences across alignments, however. Whereas regulation does not matter (statistically) when DMs are aligned with consumers $(\mathrm{KW} ; \mathrm{n}=19 ; \mathrm{p}=0.79)$, nor with independent DMs $(\mathrm{KW} ; \mathrm{n}=22$; $\mathrm{p}=0.19$ ), IA-aligned DMs do respond differently to distinct forms of regulation (KW; $\mathrm{n}=18 ; \mathrm{p}<0.01)$. Specifically, DMs who share interests with the investor choose much higher prices (on average 4.25) when they must fix the price in the first period (SR). The average price decreases as changes in regulation become easier (2.33 in ER; 2.13 in CR; and 1.50 in UR). Note that this effect cannot straightforwardly be attributed to differences in electoral competition. In all regulation treatments, a DM needs to be elected to make money. Hence, a DM that chooses a high price in period 1 of UR may be subject to punishment (by way of not being elected) by the consumers in subsequent periods (we discuss observed voter behavior below). This result does show that when political decision makers have interests that are aligned with those of the provider of an infrastructure, inflexible price regulation may have consequences opposite to those that were intended by the regulation in the first place (i.e., high instead of low prices).

Next, consider the investment decision, i.e., the average number of periods (out of six) in which no investment is observed (I6). Here, the differences across alignment conditions are statistically insignificant $(\mathrm{KW} ; \mathrm{n}=59 ; \mathrm{p}=0.26)$, as are differences across alignment for each regulation treatment separately. ${ }^{23}$ Similarly, we observe that distinct frameworks do not affect investment, neither for all preference alignments in aggregate $(\mathrm{KW} ; \mathrm{n}=59 ; \mathrm{p}=0.79)$ nor for any specific alignment. ${ }^{24} \mathrm{We}$ will show below, however, that the lack of significance stems from inefficient (irrational) first-period investments.

We next investigate treatment differences in efficiency. We do so with data from all nine periods, because surplus consequences of early-period decisions are most severe in the final three periods. We again start with the effects of DMs' alignment. Across all types of regulation, alignment matters, in a statistical sense $(\mathrm{KW} ; \mathrm{n}=59 ; \mathrm{p}=0.02)$. In general,

\footnotetext{
${ }^{21}$ In our statistical testing, we use the (statistically) independent group as the unit of observation.

${ }^{22}$ UR: KW; $n=14 ; p<0.01$; CR: KW; $n=17 ; p<0.01$; SR: KW; $n=12 ; p=0.02$; ER: Mann Whitney (MW); $n=16$; $\mathrm{p}<0.01$.

${ }^{23} \mathrm{UR}$ : KW; $\mathrm{n}=14 ; \mathrm{p}=0.44 ; \mathrm{CR}: \mathrm{KW} ; \mathrm{n}=17 ; \mathrm{p}=0.98$; SR: KW; $\mathrm{n}=12 ; \mathrm{p}=0.22$; $E R: \mathrm{MW} ; \mathrm{n}=16 ; \mathrm{p}=0.58$.

$\left.{ }^{24} \mathrm{CA}: \mathrm{KW}, \mathrm{N}=19 ; \mathrm{p}=0.72\right)$; IA: $(\mathrm{KW} ; \mathrm{N}=18 ; \mathrm{p}=0.54) ; \mathrm{N}$ : $(\mathrm{KW} ; \mathrm{N}=22 ; \mathrm{p}=0.74)$.
} 
efficiency is slightly lower when DMs share interests with the consumers. ${ }^{25}$ For UR (KW; $\mathrm{n}=14 ; \mathrm{p}=0.94), \mathrm{CR}(\mathrm{KW} ; \mathrm{n}=17 ; \mathrm{p}=0.28)$ and $\mathrm{ER}(\mathrm{MW} ; \mathrm{n}=16 ; \mathrm{p}=0.51)$ there are no significantly different effects of alignment, however. In SR, efficiency is much lower when DMs share interests with the IOs, because they set inefficiently high prices. This effect is significant $(\mathrm{KW} ; \mathrm{n}=12 ; \mathrm{p}=0.02)$. Turning to the effects of variations in the type of regulation, in aggregate there are no statistically significant effects $(\mathrm{KW} ; \mathrm{n}=59 ; \mathrm{p}=0.47)$. Differences are also insignificant for consumer-aligned DMs $(\mathrm{KW} ; \mathrm{n}=19 ; \mathrm{p}=0.51)$ and non-aligned DMs $(\mathrm{KW} ; \mathrm{n}=22 ; \mathrm{p}=0.45)$. When considering only investor-aligned $\mathrm{DMs}$, the difference in efficiency for distinct types of regulation is highly significant, however $(K W ; n=18 ; p<0.01)$. Again this may be attributed to the case of IA-aligned DMs in SR, where the inflexible nature of the price regulation yields high prices.

All in all, the outcome in terms of prices and efficiency depend on both treatment dimensions. The treatment that appears to be most detrimental for consumer prices and efficiency is where decision makers' interests align with investor and regulation forces them to decide on a fixed price in the first period, thus taking away any chance that future electoral competition will put a downward pressure on prices. ${ }^{26}$ In contrast, when DMs interests align with those of the consumers, the type of regulation has little effect on the prices chosen by the decision maker: these are typically low. As a consequence, investment then tends to be postponed, but not abandoned. This yields outcomes with negative yields for the investors.

\section{A subsample conditioning on period 1 behavior}

One noticeable result in our data is the large number of investors that invest in the first period (45.8\% of the IOs do so; cf. figures 2 and 3). Recall that this implies making an irreversible decision before having observed any behavior (or any cheap talk) from the other participants. Moreover, no learning can take place across investment decisions, because each investor only takes part in a single 9-period game. The decision to invest in period 1 is statistically independent of the type of regulation $(\mathrm{KW} ; n=59 ; \mathrm{p}=0.98)$ and alignment $(\mathrm{KW} ; \mathrm{n}=59 ; \mathrm{p}=0.22)$. Because investment in period 1 is never profitable (IO's earnings are higher if she does not invest in period 1), we consider the possibility that these are caused by inexperienced subjects

\footnotetext{
${ }^{25}$ Note from Table 4 that differences are small, however, i.e., between 0.92 for CA and 0.94 for N.

${ }^{26}$ Note that the efficiency in the (UR, CA) cell is even lower, but the difference is not significant in the rowwise and column-wise comparisons.
} 
making errors. ${ }^{27}$ Hence, we tested for treatment effects in investment decisions by IOs, conditional on them not having invested in period 1.

First, consider the effect of alignment. The average value of I6 (number of periods without investment) is 4.08, 3.00, and 4.44, for CA, IA and N, respectively (recall that for prices guaranteed to be- equal to 1 , a money maximizing IO will invest in period 4 , i.e., I6=3). Hence, conditional on not investing in period 1, the first period in which IOs invest is on average sooner when the DMs' preferences are aligned with their own. The difference across the three alignment treatments are statistically insignificant $(\mathrm{KW} ; \mathrm{n}=32 ; \mathrm{p}=0.17)$, but the difference between IA and non-IA is weakly significant (Mann-Whitney -henceforth, MW-; $\mathrm{n}=32 ; \mathrm{p}=0.08)$.

As for differences across regulation treatments in this subsample, the number of periods without investment is on average 5.16, 3.36, 2.58, 4.43, for UR, CR, SR, and ER, respectively. This shows that IOs who do not invest in the first period of the unstable regulation treatment, understand the diverging effects of regulation on prices and on average postpone investments until after the $5^{\text {th }}$ period (of the 6 periods under investigation). The differences across regulation treatments are statistically significant $(\mathrm{KW} ; n=32 ; p=0.03)$.

To illustrate investment behavior by this subgroup, figure 4 shows average investment per period for each type of regulation. It does so separately for the cases where the DMs' interests are aligned with IA's and the cases where it is not (CA and N). Note that for IA (left panel) the different types of regulation yield only minor differences in investment patterns, whereas investments strongly depend on regulation for alignments $\mathrm{CA}$ and $\mathrm{N}$. The differences for IA are statistically insignificant $(\mathrm{KW} ; \mathrm{n}=10 ; \mathrm{p}=0.93)$, those for the combination of $\mathrm{CA}$ and $\mathrm{N}$ are strongly significant $(\mathrm{KW} ; \mathrm{n}=22 ; \mathrm{p}<0.01)$. As long as IOs and DMs share interests, investment will take place near the optimal period. When their interests differ such optimal investment is only observed when prices can be fixed across future elections (as in SR). Full investments are also observed (but often too late) when price changing is costly. In ER investment is not complete because electoral competition induces many DMs to fix the price to 0, making investment unprofitable.

\footnotetext{
${ }^{27}$ Alternatively, IOs may invest in the (mistaken) expectation that this will be reciprocated by DMs choosing high prices. This too, may be considered as a kind of error.
} 
Figure 4: Investments versus Regulation; if not Invested in Period 1

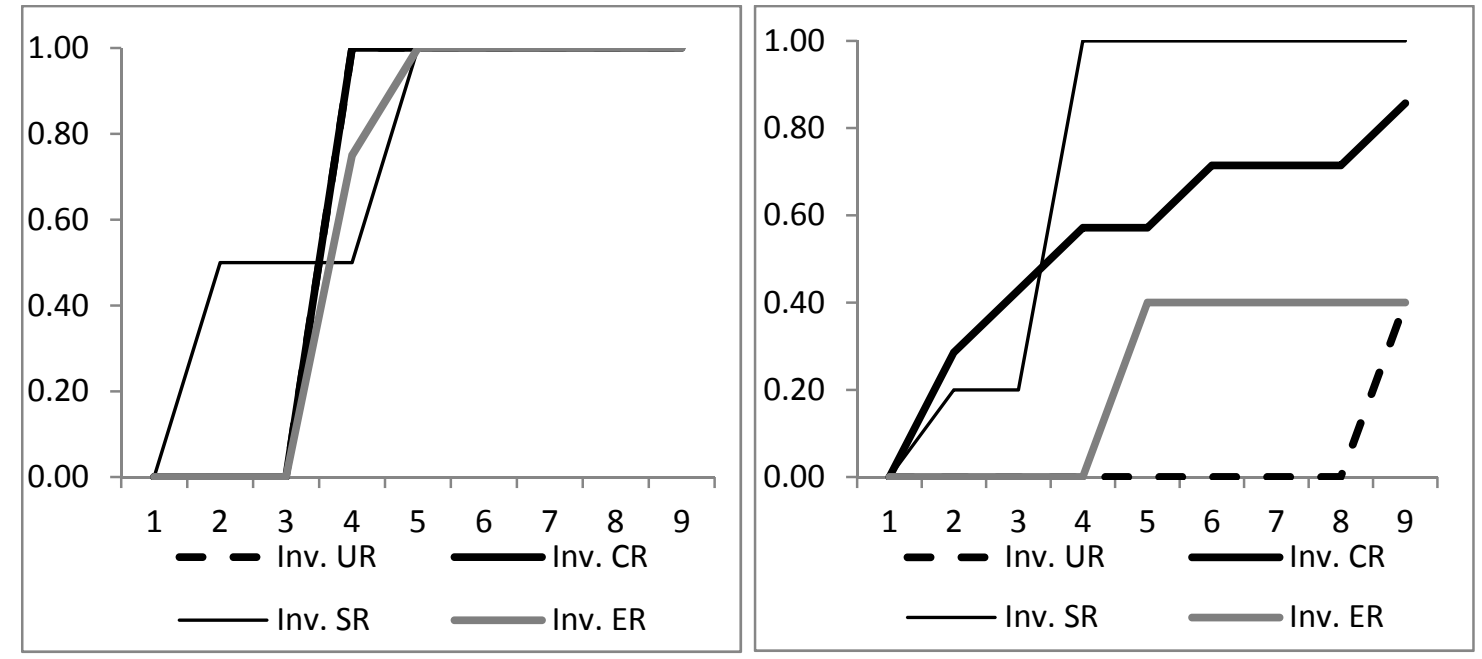

Notes. The figure shows the fraction of groups in which investment has occurred (vertical axis) for each period (horizontal axis), for those IOs who have not invested in period 1. The left panel $(n=10)$ shows investments for IA (DMs' preferences are aligned with IOs); the right panel $(n=22)$ combines investments for CA (DMs' preferences aligned with CVs') and $\mathrm{N}$ (independent preferences for DMs). In the left panel, the line for UR is not visible because it coincides with CR. Inv.=Investment; $[\mathrm{UR}]=$ Unstable Regulation (prices freely chosen each period); [CR]: Costly Regulation (prices changed at a cost); [SR]: Stable Regulation (prices fixed in period 1); [ER]: Endogenous Regulation (price determiner chooses whether or not to fix the price).

\section{Voting Behavior}

When deciding on which DM to vote for, a consumer can use either the DM's previous price choice, her announced price in the current period or both. To analyze this decision, we will distinguish between first and later period votes. For the latter, we will investigate the extent to which voters weigh currently promised prices versus previously chosen prices by the DMs.

Table 5 first shows the results of a probit model explaining the probability that a consumer will vote for DM2 as opposed to DM1. ${ }^{28}$ The results show that prior investment and period number have no effect on the decision on which DM to support. This is as expected, because neither of these variables per se is informative about either DM. How the DMs' proposals are relative to the price suggested by the investor has no significant effect; the investor's proposed price appears to be considered irrelevant. DMs' proposals matter in all periods, however. In period 1, when no other information is available to the consumer to distinguish between the two DMs, a unit increase in the difference in proposed price by DM1 and DM2 increases the probability of a vote for

\footnotetext{
${ }^{28}$ Random effects are introduced at the group level in order to correct for interdependencies across the three consumers in a group.
} 
Table 5: Consumers' Voting

\begin{tabular}{|l|c|c|}
\cline { 2 - 3 } \multicolumn{1}{c|}{} & \multicolumn{2}{c|}{ All Treatments } \\
\cline { 2 - 3 } \multicolumn{1}{c|}{} & Period 1 & Period 2-9 \\
\hline period & --- & $-0.003(0.01)$ \\
\hline Invested & $0.090(0.08)$ & $-0.016(0.05)$ \\
\hline$\Delta$ proposal DM1-DM2 & $0.290(0.05)^{* * *}$ & $0.136(0.03)^{* * *}$ \\
\hline$\Delta$ proposal DM1-I & $0.053(0.03)$ & $-0.015(0.01)$ \\
\hline LastPequal & --- & $-0.034(0.05)$ \\
\hline LastP2higher & --- & $-0.229(0.06)^{* * *}$ \\
\hline LastP2lower & --- & $0.263(0.07)^{* * *}$ \\
\hline $\mathrm{n}$ & 177 & 1416 \\
\hline
\end{tabular}

Notes. The table presents the results of a probit model with robust standard errors clustered at the group level. The binary dependent variable is $1(0)$ if the voter voted for DM2 (DM1). It gives the estimated marginal effects of variations in the dependent variables Standard deviations are in parentheses. 'Period' denotes the period number; 'Invested' $=1(0)$ if there was investment in period $\mathrm{s} \leq \mathrm{t}$; ' $\Delta$ proposal DM1-DM2' is the difference in proposed price between DM1 and DM2; ' $\Delta$ proposal DM1- I' is the difference between DM1's proposal and I's proposal; 'LastPequal' $=1(0)$ if both DMs have determined a price in a previous period and the most recent prices chosen are (un)equal; 'LastP2higher' $=1(0)$ if both DMs have determined a price in a previous period and the most recent prices chosen by DM2 is (not) higher; 'LastP2lower' $=1(0)$ if both DMs have determined a price in a previous period and the most recent prices chosen by DM2 is (not) lower. For the latter three variables, prices of 2 or higher are considered to be equal.

$*(* * / * * *)$ denotes statistical significance at the $10 \%(5 \% / 1 \%)$-level.

DM2 by $29 \%$-points. ${ }^{29}$ The effect of differences in promised prices reduces to $14 \%$-points in later periods, where consumers have information about what the DMs had actually chosen after having been elected in a previous period. ${ }^{30}$ Differences in actual choices matter: having previously chosen a higher price than DM1 decreases DM2's chances of election by $23 \%$ points, whereas a previous lower price than DM1 increases it by $26 \%$-points. Note that this effect is similar in size to that of differences in proposals in period 1, when consumers do not yet have information about actually chosen prices. Note that these effects are symmetric and larger than the estimated effect of the DMs' proposals in the current period. Finally, as expected, previous price choices by the DMs have no effect on the consumers' choices if they were equal.

All in all, the CVs in our experiment tend to vote 'rationally'. They care only about the DMs' prices and substitute information about actual price choices for cheap talk proposals

\footnotetext{
${ }^{29}$ These marginal effects are determined at the mean values of the independent variables. They are not constant. Hence, this estimated value should not be taken to imply that large differences in proposed prices would yield percentage point differences of more than $100 \%$.

${ }^{30}$ The benchmark for the three dummy variables related to actual previous choices is the situation where one of the DMs has not yet been elected in an earlier period.
} 
when the former is available. Nevertheless, proposals do still have an effect, even when the consumers know what the DMs actually did in earlier periods.

Next, we consider whether CVs take into account the DMs interest in the prices. Table 6 shows the probit results for each alignment separately.

Table 6: Consumers' Voting per Alignment

\begin{tabular}{|c|c|c|c|}
\hline & \multicolumn{3}{|c|}{ Period 1} \\
\hline & $\mathrm{CA}$ & IA & $\mathrm{N}$ \\
\hline Invested & $0.204(0.16)$ & $0.169(0.13)$ & $-0.050(0.16)$ \\
\hline$\Delta$ proposal DM1-DM2 & $0.296(0.07)^{* * *}$ & $0.230(0.07)^{* * *}$ & $0.426(0.11)^{* * *}$ \\
\hline$\Delta$ proposal DM-I & $-0.024(0.05)$ & $0.030(0.11)$ & $0.093(0.08)$ \\
\hline \multirow[t]{2}{*}{$\mathrm{n}$} & 57 & 54 & 66 \\
\hline & \multicolumn{3}{|c|}{ Periods 2-9 } \\
\hline Period & $0.001(0.01)$ & $0.012(0.02)$ & $-0.017(0.01)$ \\
\hline Invested & $-0.0324(0.06)$ & $0.038(0.08)$ & $-0.065(0.08)$ \\
\hline$\Delta$ proposal DM1-DM2 & $0.263(0.06)^{* * *}$ & $0.057(0.04)$ & $0.215(0.09)^{* * *}$ \\
\hline$\Delta$ proposal DM1-I & $-0.028(0.02)$ & $0.018(0.02)$ & $-0.013(0.01)$ \\
\hline LastPequal & $-0.010(0.07)$ & $-0.033(0.10)$ & $-0.066(0.06)$ \\
\hline LastP2higher & $-0.188(0.13)$ & $-0.245(0.09) * * *$ & $-0.135(0.10)$ \\
\hline LastP2lower & $0.094(0.07)$ & $0.118(0.10)$ & $0.325(0.08)^{* * * *}$ \\
\hline $\mathrm{n}$ & 456 & 432 & 528 \\
\hline
\end{tabular}

Notes. The regression model and independent variables are described in the note to Table 5. CA=Consumeraligned DMs; IA=Investor-aligned DMs; $\mathrm{N}=$ Neutral DMs.

$*(* * * * *)$ denotes statistical significance at the $10 \%(5 \% / 1 \%)$-level.

Consider first the votes in period 1. As for the aggregate case, only the difference in proposed prices by the two DMs significantly affects the vote, with the lower price proposal yielding more votes. The marginal effects differ strongly, however. For IA, this effect is three-quarters of what it is for CA and just over half of what it is for N. Apparently, the consumers realize that the DMs in IA have an incentive to set high prices, and therefore trust the proposals less than in the other treatments, even though these proposals are all they have to base their decisions on in period 1. For each alignment, the marginal effects of these differences in proposals decrease in later periods, when the DMs build a price setting reputation. For IA, differences in proposed prices no longer significantly affect the probability of being elected. Instead, voters rely more on the DMs' actual previous choices. This does not hold for CA and $\mathrm{N}$, where promises have a strong effect, even when evidence of past behavior is available. Note, however, that statistical power for the effects of actual relative previous choices is low for some of the significance tests. This is because DMs often agree on what price to choose. 
As a consequence, for CA we have only eight observations where the most recent price chosen by DM1 is larger than that chosen by DM2 (i.e., LastP2lower =1). Similarly, in N we have only six observations where LastP2higher=1). Taking this into account, we can draw only tentative conclusions from the tests that do have sufficient power.

All in all, the disaggregated analysis of Table 6 confirms that consumers tend to vote rationally in our experiments. They take into account that DMs interests are likely to affect the prices to be chosen and adjust the weight they attach to promises and previous prices accordingly.

\section{Testing the Hypotheses}

We finalize the presentation of the results by formally testing the hypotheses presented in Section 3. We will repeat each hypothesis and present analysis by statistical tests.

H1. Investment will happen earlier in treatments that permit fixing the regulated price (SR and ER) than in treatments where the price cannot be fixed (UR and CR).

Formally, we test whether we can reject the null of no difference in investment period in favor of H1. On average, investment occurs after 2.34 periods in SR/ER and 2.70 periods in UR/CR. To test the hypothesis, we need to correct for the fact that the decision to invest only needs to be made if investment has not previously taken place. We therefore ran a probit regression with robust standard errors (clustered at the investor level) explaining any decision to invest when there was no previous investment (i.e., disregarding all periods after investment). The explanatory variables include a dummy for the first period (which yields a positive and highly significant coefficient; this reflects the fact that many IOs invest immediately, irrespective of the treatment). The other explanatory variables are the period number; a dummy representing the SR and ER treatments; and an interaction of period with this dummy. None of these explanatory variables yields a statistically significant result. The reason becomes clear from table 4 and figure 4: investments take place early in SR, but not in ER. We therefore ran a similar probit regression, replacing the SR-and-ER dummy by one that distinguishes only the SR treatment. Now the interaction between period and SR is significantly positive at the $1 \%$ level (a marginal effect of $0.17, \mathrm{p}<0.01$ ), indicating that as rounds progress in SR, it becomes more likely that IO will invest. In contrast the effect of round is much smaller and insignificant for the other treatments (a marginal effect of 0.01, 
$\mathrm{p}=0.58$ ). Hence, investment is estimated to occur significantly earlier in SR than in the other regulation treatments. ${ }^{31}$

H2. Prices will be higher in treatments that permit fixing the regulated price (SR and ER) than in treatments where the price cannot be fixed (UR and CR).

With an average of 1.37, prices are indeed higher in ER and SR than in UR and CR, where on average they are 0.90 . Testing against the null of no difference, the observed difference is not significant using a nonparametric test (MW; $n=59 ; p=0.34)$. Again, this may be related to behavior in ER that is different than predicted. As noted in the discussion following table 4, average prices depend strongly on the regulation treatment when interests of IOs and DMs are aligned. Considering only IA, we find that prices are much higher in SR (4.25) than in the other treatments (2.38). This difference is highly significant (MW; $\mathrm{n}=18 ; \mathrm{p}<0.01$ ).

H3. Except in the final period, the DMs' preferences do not affect investment or prices. In the final period the prices will be higher when the DMs' interests are aligned with those of the investor [IA] and the prices cannot be fixed (treatments [UR] and [CR]).

The discussions on Table 4 provide evidence against the first part of this hypothesis. They show that the DMs' preferences do matter. In particular, alignment with the IO yields higher prices and earlier investment (especially for the subgroup that does not invest in period 1). Though the DMs are rewarded by consumers for suggesting and choosing lower prices, this turns out to be insufficient to create an electoral competition that lowers prices to the levels observed in the other treatments. In period 9, average prices in the treatments [IA+UR] or $[\mathrm{IA}+\mathrm{CR}]$ are always equal to 5 . The average price in other treatments is 1.38 . The difference is statistically significant ( $\mathrm{MW} ; \mathrm{n}=59 ; \mathrm{p}<0.01)$. This provides support for the second part of the hypothesis.

H4: Voters are less likely to vote to reelect the incumbent after she previously chose a price of 2 or more than after a lower price. In UR and CR, voters are less likely to vote to reelect the incumbent after she previously chose a price of 1 than after a price of 0 .

\footnotetext{
${ }^{31}$ The estimated marginal effect for the SR dummy is -0.19 , n.s.). Hence, from period 2 onward, IOs in SR are estimated to be more likely to invest $(-0.19+2 * 0.17=0.32>2 * 0.01)$.
} 
The analysis provided above shows that voters respond to price differences between the two DMs and thus show evidence of rational voter behavior. Neither of these two specific hypothesis finds support, however. Using probit analysis (with the robust standard errors at the group level) to explain voting for the incumbent, a dummy variable denoting prices of 2 or higher yields statistically insignificant coefficients in various specifications. Similarly, for UR and CR a dummy variable for prices 1 (instead of 0 ) also yields only insignificant coefficients). Our earlier analysis of voter behavior reveals that voters may be slightly more rational than is assumed in this hypothesis. They not only consider the incumbent's most recent choices, but also the most recent choices of the other DM, when she had last been in office.

\section{Conclusions}

Large infrastructure is often owned by private investors with the right to charge usage fees. In industries such as power or gas delivery the transmission networks represent natural monopolies where price regulation is necessary for efficiency. Periodic upgrades to the transmission infrastructure may, however, require significant irreversible investment with long-term return spanning several decades. Investors thus face uncertainty in their return in many dimensions: from highly unpredictable shifts in future demand to shifts in technology. In this paper we investigate a particular type of uncertainty, arising from unpredictable changes in price regulation when regulators are subject to electoral competition.

A model of investment in markets where regulation is subject to varying degrees of political manipulation suggests that investment is efficient only with independent regulation. If voters cannot affect prices through their elected decision-makers then, in theory, investment will be timely. On the other hand, if regulation cannot be separated from electoral dynamics, then investment may never occur, as investors expect that electoral competition will drive prices unsustainably low.

We verify the model predictions via a laboratory experiment with human subjects. The predictions are only partially confirmed by the data. On average the infrastructure owners indeed delay investment if regulation is separated from electoral dynamics, but the effect on resulting prices is marginal. We observe a much stronger effect of decision makers' private preferences. Prices are significantly higher and investment earlier when decision makers' interests align with those of investors. Despite the electoral competition the regulation in this 
case is lax, allowing prices to rise far above the efficient levels. Such high prices decrease general efficiency despite the early investment they induce. In contrast to the decision makers' preference alignment, the regulation framework has only a marginal effect for efficiency.

As a consequence, efficiency is affected by the interaction between the vulnerability of prices to political manipulation on the one hand and the interests of politicians on the other. If politicians' interests align with those of the infrastructure operators, rigid regulation will be detrimental to efficiency. Though investment is stimulated in this scenario, inefficiencies arise because regulation is made lax and independent of the electoral pressure, leading to permanently high prices. Even with less rigid regulation the electoral competition between two politicians may not be strong enough to prevent their pursuit of their own interests at the costs of the electorate. In contrast, rigid regulation benefits efficiency if politicians' interests are not aligned with investors. This is because such stable regulations motivates politicians to commit to minimal prices that make investment profitable to the infrastructure operator. These differential effects of politicians' interests were not predicted by theory, but showed up in our laboratory experiments.

Our results thus highlight the limits of the intuition that an independent regulatory is beneficial for the consumers. This intuition only holds when regulation policy is designed with the interests of the consumers in mind. The regulation efficiency strongly depends on the interests of its designer. If its independency is high the original designer's interests have a long lasting impact. If the political interests align with infrastructure operators a limited regulatory independence is therefore more efficient.

\section{References}

Banks, J., \& Duggan, J. (2006): “A General Bargaining Model of Legislative Policy-making”, Quarterly Journal of Political Science, 1, 49-85.

Brandts, J., P. Pezanis-Christou and A. Schram (2008): "Competition with Forward Contracts: A Laboratory Analysis Motivated by Electricity Market Design”, The Economic Journal, $118,192-214$

Brandts, J., S. Reynolds and A. Schram (2012): "Pivotal Suppliers and Market Power in Experimental Supply Function Competition", CREED working paper, University of Amsterdam.

Campillo, J., F. Wallin, and E. Dahlquist (2012): "Electricity Demand Impact from Increased use of Ground Sourced Heat Pumps,", paper presented at the $3^{\text {rd }}$ IEEE Innovative Smart Grid Technologies Europe, Berlin.

Cox, J., T. Offerman, M. Olson and A.Schram, "Competition for vs on the Rails, a Laboratory Experiment”, International Economic Review 43, 2002, 709-735. 
Brunner, Ch., J.K. Goeree, Ch. A. Holt, and J. O. Ledyard (2010): “An Experimental Test of Flexible Combinatorial Spectrum Auction Formats", American Economic Journal: Microeconomics 2010, 2:1, 39-57.

Enikolopov, R, (2012): "Politicians, Bureaucrats and Targeted Redistribution", working paper, available at SSRN: http://dx.doi.org/10.2139/ssrn.945274.

Kessides (2004): "Reforming Infrastructure: Privatization, Regulation, and Competition", World Bank report.

Falk, A. and J. Heckman(2009), "Lab Experiments Are a major Source of Knowledge in the Social Sciences," Science 326:535-538.

Klein, M. and Ph. Gray (1997), "Competition in Network Industries - Where and How to Introduce it," Public Policy for the Private Sector Note 104, World Bank.

Ponti, M. and S. Erba (2002), "Railway Liberalization from a "Public Choice" Perspective," Quarterly Journal of Transport Law, Economics and Engineering VII (20-21): 38-46.

Rassenti, S., V. Smith and B. Wilson (2002): "Using experiments to Inform the Privatization/Deregulation Movement in Electricity", The Cato Journal, 22, 3, winter 2002.

Staropoli C. and C. Jullien (2006): "Using Laboratory Experiments to Design Efficient Market Institutions: The Case of Wholesale Electricity Markets," Annals of Public and Cooperative Economics, 77, 4, 555-577.

Vliet, O. van, A. Brouwer, T. Kuramochi, M. van den Broek, and A. Faaij (2011): "Energy Use, Cost and $\mathrm{CO}_{2}$ Emissions of Electric Cars," Journal of Power Sources 196/4: 22982310 . 


\section{Appendix A}

This appendix contains the analysis for the model described in section 2 . We first determine the optimal pricing for each agent when the demand is fixed and game played just once, both with and without investment. We then determine the optimal investment behavior, again from the perspective of the different agents. We denote the payoffs that the IO and a CV maximize respectively by $\pi^{\mathrm{I}}$ and $\pi^{\mathrm{V}}$.

We measure efficiency with the sum of the IO's all CVs' profits $\pi^{\mathrm{I}}+\mathrm{n} \pi^{\mathrm{V}}$, that is, with the total surplus from service consumption. Given linear demand and zero marginal costs of IO's service, this is maximized when $\mathrm{P}=0$. Investment is then socially efficient when the benefits from additional service consumption it enables exceed its costs. Let $\mathrm{P}^{\text {cst }}$ be the price where demand equals capacity constraint $\mathrm{Q}\left(\mathrm{P}^{\text {cst }}\right)=\mathrm{Q}^{\text {cst }} ; \mathrm{P}^{\text {cst }}=\mathrm{P}^{\text {max }}-\mathrm{Q}^{\text {cst }} / \mathrm{nb}$. Investment is therefore efficient when $\left(\mathrm{Q}(0)-\mathrm{Q}^{\text {cst }}\right) \mathrm{P}^{\text {cst }} / 2>\mathrm{c}$. Rewriting this yields the following relation between demand parameters and investment efficiency:

$$
\mathrm{P}^{\max }\left(n b \mathrm{P}^{\max }-\mathrm{Q}^{\mathrm{cst}}\right)>2 \mathrm{c}
$$

\section{Pricing with investment}

The IO can provide any quantity of service (electricity) but incurs cost c. If it chooses a price $\mathrm{P} \in\left[0, \mathrm{P}^{\max }\right]$ and delivers quantity $\mathrm{Q}(\mathrm{P})=\mathrm{nb}\left(\mathrm{P}^{\mathrm{max}}-\mathrm{P}\right)$, it obtains profit $\pi^{\mathrm{I}}(\mathrm{P})=\mathrm{PQ}(\mathrm{P})-\mathrm{c}=$ $n b P\left(P^{\max }-\mathrm{P}\right)-\mathrm{c}$. This yields a surplus $\pi^{\mathrm{V}}(\mathrm{P})=\mathrm{b}\left(\mathrm{P}^{\max }-\mathrm{P}\right)^{2} / 2$ to any $\mathrm{CV}$.

- The IO maximizes its profit with the monopoly price $\mathrm{P}^{*}=\mathrm{P}^{\max } / 2$, found through $\mathrm{Q}^{*}=\mathrm{nbP}^{\max } / 2$ and $\mathrm{P}^{*}=\mathrm{P}^{\max }-\mathrm{Q}^{*} / \mathrm{nb}$. This yields it the monopoly profit $\pi^{\mathrm{I} *}=\mathrm{P}^{*} \mathrm{Q} *=\mathrm{nb}\left(\mathrm{P}^{\max }\right)^{2} / 4-\mathrm{c}$. It also yields a surplus $\pi^{\mathrm{V} *}=\mathrm{b}\left(\mathrm{P}^{\max }\right)^{2} / 8$ to each $\mathrm{CV}$.

- The regulated IO will choose price $\mathrm{P}=\min \left\{\mathrm{P}^{*}, \mathrm{P}^{\mathrm{reg}}\right\}$ and earn $\pi^{\mathrm{I}}=\mathrm{PQ}(\mathrm{P})-\mathrm{c}$, yielding $\pi^{\mathrm{V}}=\mathrm{b}\left(\mathrm{P}^{\max }-\mathrm{P}^{\mathrm{reg}}\right)^{2} / 2$ to a $\mathrm{CV}$. The $\mathrm{CV}$, however, maximizes its surplus when $\mathrm{P}^{\mathrm{reg}}=0$, with $\pi^{\mathrm{Vo}}=\mathrm{b}\left(\mathrm{P}^{\mathrm{max}}\right)^{2} / 2$. This yields a loss $\pi^{\mathrm{Io}}=-\mathrm{c}$ to the IO.

- The IO has zero profit when $\mathrm{PQ}(\mathrm{P})=\mathrm{c}$, that is, when $\mathrm{P}=\left(\mathrm{P}^{\max }-\sqrt{ }\left[\left(\mathrm{P}^{\max }\right)^{2}-4 \mathrm{c} / \mathrm{nb}\right]\right) / 2$. We can determine other solutions for the IO, e.g. if it pays a tax or if its profit has an upper bound or if its profit per unit has an upper bound etc.

The interests of the three parties may be in conflict. If the $\mathrm{DM}^{\mathrm{E}}$ wants to appease the voters it might choose to regulate a low price that yields the IO a loss. The monopoly price increases only with $\mathrm{P}^{\max }$.

\section{Pricing without investment}

In absence of investment the IO provides at most $\mathrm{Q}^{\mathrm{cst}}$ units of service (electricity). ). If it chooses a price $\mathrm{P} \in\left[0, \mathrm{P}^{\max }\right]$ and delivers quantity $\mathrm{Q}(\mathrm{P})=\min \left\{\mathrm{nb}\left(\mathrm{P}^{\max }-\mathrm{P}\right), \mathrm{Q}^{\text {cst }}\right\}$ it obtains profit $\pi^{\mathrm{I}}(\mathrm{P})=\min \left\{\mathrm{nbP}\left(\mathrm{P}^{\mathrm{max}}-\mathrm{P}\right), \mathrm{PQ}^{\text {cst }}\right\}$. 
- If $\mathrm{P}<\mathrm{P}^{\max }-\mathrm{Q}^{\text {cst }} / \mathrm{nb}$ the demand exceeds the max possible supply $\mathrm{Q}^{\text {cst }}$. In this case it would have been better for the CVs (but not necessarily for IO or the efficiency) if IO invests.

- An unregulated IO chooses $\mathrm{P}^{*}$ when this leads to a demand below capacity constraint. The capacity constraint is an issue only when $\mathrm{Q}^{\text {cst }}<\mathrm{Q}^{*}$. In this case IO would set the price $\mathrm{P}=\mathrm{P}^{\max }-\mathrm{Q}^{\mathrm{cst}} / \mathrm{nb}$, above the monoply price $\mathrm{P} *$ it would set had it invested. The IO's profit is then $\pi^{\mathrm{I}}(\mathrm{P})=\mathrm{Q}^{\text {cst }}\left(\mathrm{P}^{\mathrm{max}}-\mathrm{Q}^{\text {cst }} / \mathrm{nb}\right)$ and the CVs' profit is $\pi^{\mathrm{V}}(\mathrm{P})=\left(\mathrm{Q}^{\text {cst }}\right)^{2} / 2 \mathrm{nb}$. In general, therefore, $\mathrm{IO}$ will set $\mathrm{P}=\max \left\{\mathrm{P}^{*}, \mathrm{P}^{\max }-\mathrm{Q}^{\mathrm{cst}} / \mathrm{nb}\right\}$.

- If regulated the $\mathrm{IO}$ will choose the price $\mathrm{P}=\min \left\{\mathrm{P}^{\mathrm{reg}}, \max \left\{\mathrm{P}^{*}, \mathrm{P}^{\max }-\mathrm{Q}^{\mathrm{cst}} / \mathrm{nb}\right\}\right\}$. Again, the CV maximizes its surplus when $\mathrm{P}^{\mathrm{reg}}=0$.

\section{When is investment rational or efficient?}

The unregulated IO invests when the demand is sufficiently high (exceeding the capacity constraint even with monopoly price $\left.\mathrm{P}^{*}\right)$. However, if $\mathrm{IO}$ is regulated, it might not invest even with sufficiently high demand, if the price is regulated so low that it becomes unprofitable for the monopolist to incur cost c.

For an unregulated IO the investment is profitable whenever the capacity constraint is binding and the monopoly profit after investment exceeds the monopoly profit without it. This is when $\mathrm{Q}^{\text {cst }}<\mathrm{nbP} \mathrm{P}^{\max } / 2$ and $\mathrm{nb}\left(\mathrm{P}^{\max }\right)^{2} / 4-\mathrm{c}>\mathrm{Q}^{\text {cst }}\left(\mathrm{P}^{\max }-\mathrm{Q}^{\text {cst }} / \mathrm{nb}\right)$, which implies (2).

When will a regulated monopolist invest? Say that the IO is regulated to charge price at most $\mathrm{P}^{\mathrm{reg}} \in\left(0, \mathrm{P}^{*}\right)$ irrespective of its investment. This is then exactly the price it will charge according to the rule above. Is there a $\mathrm{P}^{\max }$ for which it invests? Let the capacity constraint be an issue: $\mathrm{nb}\left(\mathrm{P}^{\max }-\mathrm{P}\right)>\mathrm{Q}^{\text {cst }}$.

- without investment the IO earns $\pi^{\mathrm{I}}=\min \left\{n b \mathrm{P}^{\text {reg }}\left(\mathrm{P}^{\mathrm{max}}-\mathrm{P}^{\text {reg }}\right), \mathrm{P}^{\text {reg }} \mathrm{Q}^{\text {cst }}\right\}$.

- with investment the IO earns $\pi^{\mathrm{I}}=n b \mathrm{P}^{\mathrm{reg}}\left(\mathrm{P}^{\max }-\mathrm{P}^{\mathrm{reg}}\right)-\mathrm{c}$

The investment is profitable for a regulated IO only when the demand sufficiently exceeds capacity: $\mathrm{P}^{\text {reg }} \mathrm{Q}^{\text {cst }}<\mathrm{nbP} \mathrm{P}^{\mathrm{reg}}\left(\mathrm{P}^{\mathrm{max}}-\mathrm{P}^{\mathrm{reg}}\right)-\mathrm{c}$, which implies (4).

Given regulation, investment is efficient only when demand exceeds capacity, as otherwise the investment cost is lost. Let this be the case. Investment yields the CVs' the added surplus from extra satisfied demand of $\left(\mathrm{Q}^{\mathrm{reg}}-\mathrm{Q}^{\mathrm{cst}}\right)\left(\mathrm{P}^{\mathrm{cst}}-\mathrm{P}^{\mathrm{reg}}\right) / 2=\left[\mathrm{nb}\left(\mathrm{P}^{\mathrm{max}}-\mathrm{P}^{\mathrm{reg}}\right)-\mathrm{Q}^{\mathrm{cst}}\right]^{2} / 2 \mathrm{nb}$. The IO earns $n b \mathrm{P}^{\text {reg }}\left(\mathrm{P}^{\mathrm{max}}-\mathrm{P}^{\mathrm{reg}}\right)-\mathrm{c}-\mathrm{P}^{\text {reg }} \mathrm{Q}^{\text {cst }}$. Together, investment with regulation is efficient when demand exceeds capacity (3) and $c<\left[n b\left(P^{\max }-P^{\text {reg }}\right)-Q^{\text {cst }}\right]^{2} / 2 n b+n b P^{\text {reg }}\left(P^{\max }-P^{\text {reg }}\right)-P^{\text {reg }} Q^{\text {cst }}$, that is, when

$$
\mathrm{c}<\mathrm{nb}\left[\left(\mathrm{P}^{\max }-\mathrm{Q}^{\mathrm{cst}} / \mathrm{nb}\right)^{2}-\left(\mathrm{P}^{\mathrm{reg}}\right)^{2}\right] / 2 .
$$




\section{When is regulation efficient?}

As the IO fails to internalize the CVs' excess surplus from investment, it may invest too late (in the sense that it requires demand to exceed capacity for more than would be efficient). This may be especially problematic when price is low. In particular, the IO will never invest if it expects the efficient price $\mathrm{P}^{\mathrm{reg}}=0$. Which price regulation is therefore efficient, given demand and IO's rational response?

- The regulated IO will invest when (3) and (4). Equation (4) can be set as

$$
\mathrm{nb}\left(\mathrm{P}^{\mathrm{reg}}\right)^{2}+\left(\mathrm{Q}^{\mathrm{cst}}-\mathrm{nbP}^{\mathrm{max}}\right) \mathrm{P}^{\text {reg }}+\mathrm{c} \leq 0
$$

which is solvable for $\mathrm{P}^{\text {reg }}$ only when $n b \mathrm{P}^{\max }>\mathrm{Q}^{\text {cst }}$, that is, when demand (given by $\mathrm{b}$ and $\mathrm{P}^{\max }$ ) is sufficiently high to possibly exceed capacity. In this case it is efficient to choose the lowest possible $\mathrm{P}^{\text {reg }}$ that still satisfies (6), determined by solving the quadratic equation

$$
P_{r}=\frac{1}{2 n b}\left(n b P^{\max }-Q^{c s t}-\sqrt{\left(n b P^{\max }-Q^{c s t}\right)^{2}-4 n b c}\right)
$$

- For low demand (when $\mathrm{nbP}^{\max }<\mathrm{Q}^{\text {cst }}$ or $\left(n b \mathrm{P}^{\mathrm{max}}-\mathrm{Q}^{\text {cst }}\right)^{2}<4 \mathrm{nbc}$ ), no $\mathrm{P}^{\text {reg }}$ will induce IO to invest and therefore setting $\mathrm{P}^{\mathrm{reg}}=0$ is efficient. For any higher demand choosing $\mathrm{P}^{\text {reg }}$ according to (7) is efficient. 


\section{Appendix B: Experimental Instructions}

What follows is a translation of the (Dutch) instructions for the treatment with investoraligned decision makers (IA) and endogenous regulation (ER). Instructions for other treatments are very similar and available upon request. Instructions were provided as html pages, which are separated by horizontal lines, below. Subject could read through the instructions at their own pace.

\section{p. $1 / 8$}

\section{Welcome}

We have reached part 2 of the experiment. Again, the instructions are simple. If you follow them carefully, you may make a lot of money. Your earnings from this part will also be paid out in euros at the end of the experiment. This will be done confidentially, one participant at a time.

Earnings in this part of the experiment are denoted in 'experimental franks'. At the end of the experiment, the franks will be converted into euros. The exchange rate used for this purpose is $\mathbf{1}$ euro for $\mathbf{5 0}$ francs.

These instructions consist of 8 pages like this. During the instructions, you can always move forward and back by using the mouse to click the 'next page ' or ' previous page ' button. In some cases, a page may not fit on your screen. If this is the case, you can use the scroll bar and your mouse to scroll through the page.

next page

p. $2 / 8$

\section{Rounds, Groups and Types}

This part of the experiment consists of 9 rounds .

For this part you are allocated to groups of 6 participants. The group composition remains constant, so you will remain in one group with the same other participants throughout. The composition of the groups is anonymous. You do not know with whom you are in a group. Similarly, others do not know whether you are with them.

In every group there are three different types of participants. More precisely, each group consists of one investor, two price-determiners and three consumers. 
At the beginning of the first round you will get to see which type you are. You will remain the same type throughout all 9 rounds.

In each round the investor delivers a product to each of the consumers. Exactly the same product is delivered to every consumer. Every consumer must buy the product. The price of the product is determined by one of the price determiners.

previous page next page

\section{p. $3 / 8$}

\section{Round}

In general terms, each round proceeds as follows.

The investor first decides whether or not to invest in the production process. An investment cannot be undone. If the investor invests in a round, then this decision holds in all subsequent rounds.

Then, the consumers choose a price determiner.

The chosen price determiner then chooses the price for the round. He or she also decides whether this price holds only for the current round, or also for all subsequent rounds.

Below, we will better explain each of these steps. First, we will explain how the prices and investment lead to earnings for the different types of participants.

previous page next page

p. $4 / 8$

\section{Earnings}

The price determiners will begin with a starting capital of 325 francs.

Additional earnings of the various types depend on

- whether or not investment has taken place;

- the determined price.

In general terms, the following holds: 
- Investment is never disadvantageous to the consumer and often profitable.

- Higher prices are good for the investor.

- Lower prices are good for the consumer.

- The price determiner which is not chosen in a round earns nothing .

- The price determiner that is chosen in a round will earn the same as the investor earns in that round.

The earnings is a round can be summarized more precisely in a table. Such tables will appear on your screen in each round. This is what they look like.

\begin{tabular}{|c|c|c|c|c|c|}
\hline \multicolumn{3}{|c|}{$\begin{array}{c}\text { NIET } \\
\text { geînvesteerd } \\
\text { Consu- Inves- } \\
\text { priis ment teerder }\end{array}$} & \multicolumn{3}{|c|}{$\begin{array}{l}\text { WEL } \\
\text { geinvesteerd } \\
\text { Consu- Inves- }\end{array}$} \\
\hline 0 & 10,00 & 0,00 & 0 & 12,00 & $-10,00$ \\
\hline 1 & 8,00 & 10,00 & 1 & 10,00 & 2,00 \\
\hline 2 & 4,50 & 12,00 & 2 & 5,00 & 8,00 \\
\hline 3 & 2,00 & 13,00 & 3 & 3,00 & 8,00 \\
\hline 4 & 0,50 & 14,00 & 4 & 1,00 & 9,00 \\
\hline 5 & 0,00 & 15,00 & 5 & 0,50 & 10,00 \\
\hline
\end{tabular}

(translation: "Niet geïnvesteerd"=no investment; "Wel geïnvesteerd"= investment; "prijs"=price; "consument"=consumer; "investeerder"=investor)

These earnings are meant as an example. The numbers in the experiment will be different. Therefore you can deduce nothing about the experiment itself from this example. Remember that the losing price determiner earns nothing in a round and the winning price determiner earns the same as the investor.

This example shows, for example, at price 2 that consumers earn 4.5 francs without investment and 5 francs with investment. At price 2 the investor and the winning price determiner earn 12 with investment and 8 without investment.

Please note: the tables change from one round to the next. We will hand out the tables for all rounds before the experiment starts.

Please note: the consumer will only see the own earnings and therefore does not know what the earnings of the investor are in various circumstances. Price determiners know the earnings of both the investor and consumers.

previous page next page 


\section{Calculation Tool}

We can imagine that it is not easy to keep track of all possible earnings at different prices and investment decisions. For this reason we offer a calculation tool in the experiment. This will appear on the lower right part of your screen. It looks like this.

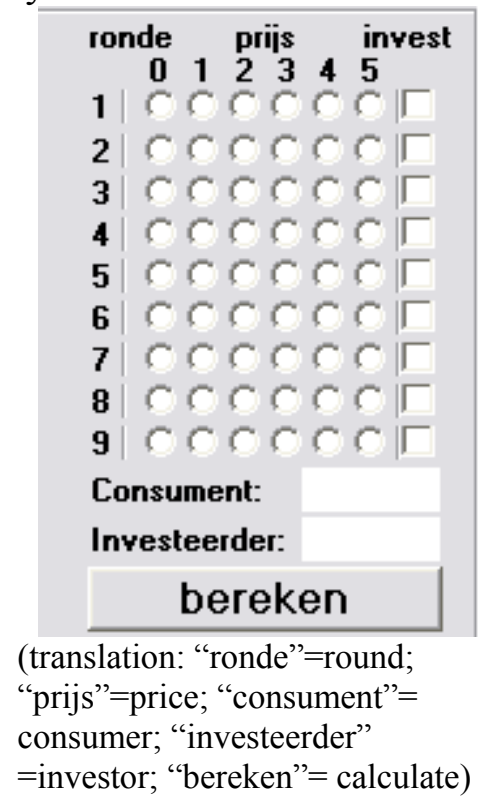

During the experiment you can use this to try out decisions and calculate what the consequences are for the earnings. You can choose a price for each round and whether investment has taken place. This is subject to the following restrictions:

- You can only make decisions from the current round onward. Previous rounds can no longer be undone. The earnings are calculated for the remaining rounds. Earnings in previous rounds are not taken into account.

- If there was investment in a previous round, investment is automatically selected in the current round. You cannot change this.

- If you choose to invest for a round, investment is automatically selected in all subsequent rounds.

- the consumers only see the own earnings, not the earnings of the investor (and winning price determiner).

In the calculation tool you fill out a price for a round. The tool then automatically chooses the same price for the subsequent rounds. You can change this by choosing a different price for a round.

If you undo an investment choice in the calculation tool, then this investment is automatically undone in all previous rounds.

previous page next page 


\section{p. $6 / 8$}

\section{Choosing a Price Determiner}

After the investor has decided about the investment we give her or him the opportunity to indicate the price he or she prefers. This is only an advice. Price determiners may decide for themselves what to do with it.

After receiving the price advised by the investor, the price determiners each propose a price. They also indicate whether the proposed price would apply only for the current round or for all remaining rounds. These proposals serve to let consumers know what they are planning. The proposed prices are not binding. The selected price determinant can deviate from the proposal when actually setting the price.

After the price determiners have announced a price and how long it would remain valid, the consumer each vote for one of the two price determiners.

The price determiner with the most votes then determines the actual price and whether this is only for the current round or for all remaining rounds. As mentioned, this decision may differ from the proposal made prior to the election.

previous page next page

\section{p. $7 / 8$}

\section{Determining the Price}

There may be a difference between determining the price in different rounds.

In the first round the price determiner can choose any price between 0 and 5 free of charge.

In later rounds the price determiner can only choose a price (free of charge) if the price has not previously been fixed for all remaining rounds.

previous page next page 


\section{In Summary}

Each round consists of six different stages. These are indicated on the left-top part of your screen by Roman numerals I-VI.

I. The investor decides on investing.

II. The investor indicates a price.

III. Price determiners propose a price and whether this only holds for the current round.

IV. The consumers choose a price determiner.

V. The chosen price determiner chooses a price (unless one was previously fixed).

VI. The earnings are calculated and communicated.

Below is an example of the screen that will be used in the experiment.

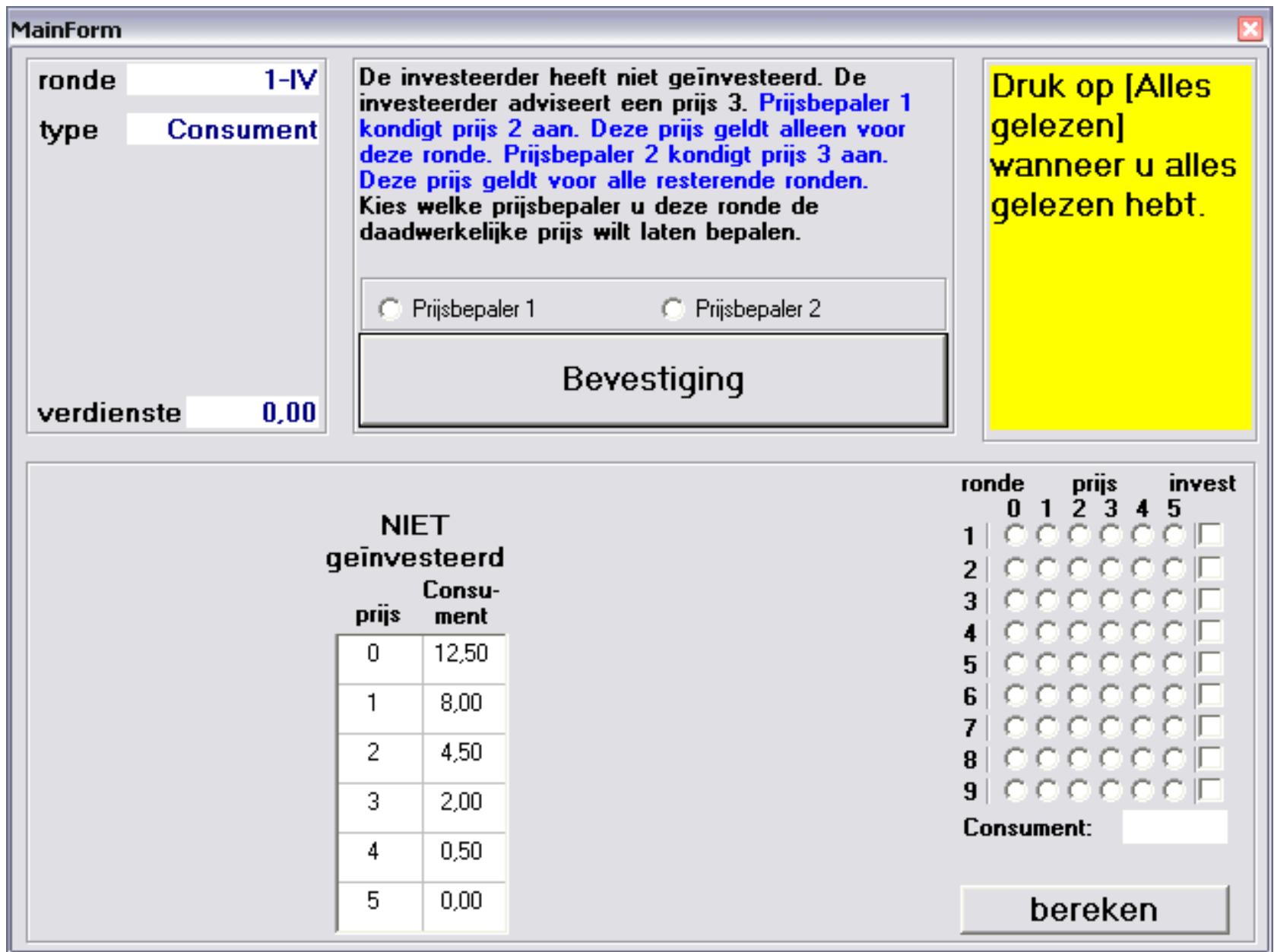

(translation: "ronde"=round; "consument"=consumer; "verdienste"=earnings; "Niet geïnvesteerd"= no investment; "prijs"=price; "De investeerder heeft niet geïnvesteerd"=The investor has not invested; "De investeerder adviseert een prijs 3"=The investor indicates price 3; "Prijsbepaler 1 kondigt prijs 2 aan. Deze prijs geldt alleen voor deze ronde."= Price determiner 1 proposes price 2 . This price holds only in the current round; "Prijsbepaler 1 kondigt prijs 3 aan. Deze prijs geldt voor alle resterende ronden."= Price determiner 2 proposes price 3. This price holds for all remaining rounds; "Kies welke prijsbepaler u deze ronde de daadwerkelijke prijs 
wilt laten bepalen." = Choose which price determiner you would like to determine the actual price in this round; "Prijsbepaler"= Price determiner"; "Bevestiging"=Confirmation; "Druk [Alles Gelezen] wanneer u alles gelezen hebt"; "Click [Read everything] after you have read everything; "bereken"= calculate.

The screen consists of five Windows. At the top left you see information about the round and phase. In this example, you are in phase IV of the first round. You will also see your role. In this example, are you one of the consumers. There you will also see your earnings. Note that this is only an example. The numbers in the experiment itself are different.

At the top center you will see a window with information about previous decisions in the round. You are also informed about what will happen in this phase (IV). All decisions will be announced to all participants. After each stage you will see at the top of your screen in the middle window an overview of the decisions in all previous phases. The decision in the most recent phase is in Blue.

At the top right is a window which says what you need to do. If this is yellow, you must do something before the experiment can proceed. In this example, you must choose a price determiner. ${ }^{32}$ Please note: in a phase in which you do not need to do anything, you need to click to confirm that you have read the text on your screen.

At the bottom left you will see the tables with potential earnings in the current round. Because no investment has taken place in this example, only the table for that case is shown.

Finally you will see in the bottom right corner the previously discussed calculation tool.

This brings you to the end of these instructions. If you wish, you can scroll back to previous pages. When you are finished, you can indicate this by pressing the button below. Then, please wait quietly until everyone is ready.

previous page back to top

\footnotetext{
${ }^{32}$ Due to an error in the software, the monitor at this stage of round 1 indicated that they must confirm that they have read everything. The consumer could not proceed without choosing a price determiner, however.
} 